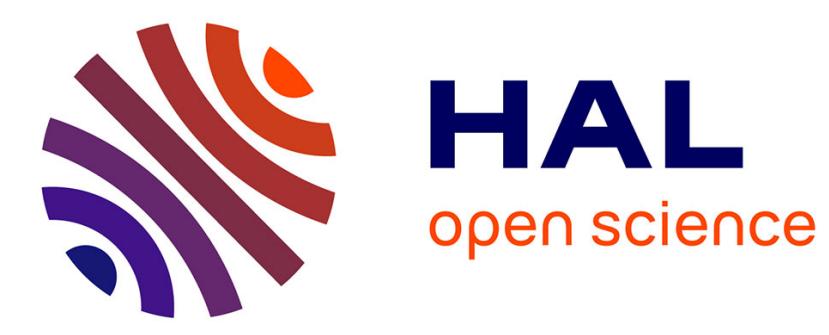

\title{
Micro-scale trigenerative compressed air energy storage system: Modeling and parametric optimization study
}

Cheayb Mohamad, Marin Gallego Mylène, Poncet Sébastien, Mohand Tazerout

\section{- To cite this version:}

Cheayb Mohamad, Marin Gallego Mylène, Poncet Sébastien, Mohand Tazerout. Micro-scale trigenerative compressed air energy storage system: Modeling and parametric optimization study. Journal of Energy Storage, 2019, 10.1016/j.est.2019.100944 . hal-02384230

\section{HAL Id: hal-02384230 \\ https://hal.science/hal-02384230}

Submitted on 2 Dec 2019

HAL is a multi-disciplinary open access archive for the deposit and dissemination of scientific research documents, whether they are published or not. The documents may come from teaching and research institutions in France or abroad, or from public or private research centers.
L'archive ouverte pluridisciplinaire HAL, est destinée au dépôt et à la diffusion de documents scientifiques de niveau recherche, publiés ou non, émanant des établissements d'enseignement et de recherche français ou étrangers, des laboratoires publics ou privés. 


\title{
Micro-scale trigenerative compressed air energy storage system: Modeling and parametric optimization study
}

\author{
Cheayb Mohamad ${ }^{\mathrm{a}, \mathrm{b}}$, Marin Gallego Mylène ${ }^{\mathrm{a}}$, Poncet Sébastien ${ }^{\mathrm{b}, *}$, Tazerout Mohand ${ }^{\mathrm{a}}$ \\ ${ }^{a}$ CNRS Joint Unit GEPEA, Department of Energy Systems and Environment, IMT Atlantique, Nantes, France \\ ${ }^{\mathrm{b}}$ Mechanical Engineering Department, Université de Sherbrooke, Sherbrooke, QC, Canada
}

\section{A R T I C L E I N F O}

\section{Keywords:}

Compressed air energy storage

Trigeneration

Thermodynamic modeling

Parametric study

Optimization

\begin{abstract}
A B S T R A C T
In this paper, a trigenerative compressed air energy storage system is considered giving priority to the electric energy production with the objective to apply it at a micro-scale, typically a few $\mathrm{kW}$. A whole detailed thermodynamic model of the system is developed including the existing technological aspects and the relations between components. The study then focuses on investigating the mutual effects of the design parameters and their influences on the system performances, energy density and heat exchanger footprints via a parametric study. From this analysis, it is found that the temperature of the thermal energy storage, the number of compression stages and the effectiveness of heat exchangers should be selected as a trade-off between the system efficiencies, heat exchangers footprints and the required number of expansion stages. Meanwhile, the selection of the maximum storage pressure is a choice whether to increase the energy density or the system efficiencies. An optimal design guideline of the above key parameters is then provided. This guideline, the method and the procedure presented in this paper can be applied to the optimization of the trigenerative compressed air energy storage and could be extended for the adiabatic one with minor changes. Based on existing technologies and using an optimal set of parameters, the round trip electrical efficiency of our system remains low at $17 \%$, while the comprehensive efficiency reaches $27.2 \%$. The poor performances are mainly linked to the exergy losses in the throttling valve and the low values of the component efficiencies at a micro-scale. The most optimization potentials are also addressed.
\end{abstract}

\section{Abbreviations}

CAES compressed air energy storage

A-CAES adiabatic CAES

T-CAES trigenerative CAES

TES thermal energy storage

AM compressed air motor

HEX heat exchanger

Pinch pinch point temperature difference

$\eta \quad$ efficiency

COP coefficient of performance

$\eta_{g} \quad$ comprehensive efficiency

\section{Introduction}

Nowadays, electrical energy storage (EES) plays a key role in integrating renewable energy sources as shown in the reviews by Luo et al. [1] and Chen et al. [2]. EES systems enable load-energy balance, meet demand peaks [3] and ensure the flexibility and reliability of grid operations [4]. Among EES technologies, compressed air energy storage CAES is considered a very promising technology. At a large scale, it is a strong alternative to the pumped hydroelectric when nearby mountains are not available $[1,5]$. In addition, at smaller scales, CAES attracted recently more attention due to their possible benefits [6-10] and their potential applications especially for off-grid sites as demonstrated by the studies of Jannelli et al. [9] and Zafirakis et al. [11].

Until now, only two commercial Compressed Air Energy Storage (CAES) installations have been operated. They have been built to minimize the fuel consumption in conventional gas turbine cycles during high demand periods [12-14]. In fact, in this simple concept of CAES called diabatic (D-CAES), the heat produced during the compression phase is wasted leading to moderate efficiencies (42\%) [13]. Recently, this technology regained attention with a major improvement, namely the use of the heat from the compression process in the expansion phase. This second generation recognized as adiabatic compressed air energy storage (A-CAES) could be competitive with others EES as found by the techno-economic study of Abdon et al. [15], thanks

\footnotetext{
* Corresponding author.

E-mail address: sebastien.poncet@usherbrooke.ca (P. Sébastien).
} 


\begin{tabular}{|c|c|c|c|}
\hline \multicolumn{2}{|c|}{ Nomenclature } & $Q_{\text {heat }}$ & heating energy $(\mathrm{kWh})$ \\
\hline $\mathrm{T}$ & temperature $\left({ }^{\circ} \mathrm{C}\right)$ & UA & heat exchanger footprint (W.K $\mathrm{K}^{-1}$ ) \\
\hline $\mathrm{P}$ & pressure (bar) & $E_{d}$ & energy density $\left(\mathrm{kWh} \cdot \mathrm{m}^{-3}\right)$ \\
\hline$\Delta P_{l}$ & pressure losses (bar) & \multirow{2}{*}{\multicolumn{2}{|c|}{ Subscripts }} \\
\hline $\mathrm{r}$ & ideal gas constant $\left(\mathrm{J} . \mathrm{K}^{-1} \cdot \mathrm{kg}^{-1}\right)$ & & \\
\hline$C_{p}$ & heat capacity $\left(\mathrm{kJ} \cdot \mathrm{kg}^{-1} \cdot{ }^{\circ} \mathrm{C}^{-1}\right)$ & & \\
\hline$N_{c}$ & number of compression stages & c & compression \\
\hline$N_{e}$ & number of turbines & e & expansion \\
\hline$n$ & polytropic coefficient & $\mathrm{i}$ & compression stage or heat exchanger number $\mathrm{i}$ \\
\hline$\beta_{c}$ & compression ratio & j & expansion stage or heat exchanger number $\mathrm{j}$ \\
\hline$\beta_{A M}$ & expansion ratio of air motor & out & output \\
\hline$\beta_{e}$ & expansion ratio of turbine & in & input \\
\hline$\dot{W}$ & power $(\mathrm{kW})$ & $\mathrm{amb}$ & ambient \\
\hline$\dot{m}$ & mass flow rate $\left(\mathrm{kg} . \mathrm{s}^{-1}\right)$ & $\mathrm{d}$ & expansion valve \\
\hline$\varepsilon$ & heat exchanger effectiveness & el & electrical \\
\hline$m_{s}$ & stored mass $(\mathrm{kg})$ & $\mathrm{m}$ & mechanical \\
\hline$\delta$ & maximum to minimum pressure ratio & th & thermodynamic \\
\hline$V$ & volume $\left(\mathrm{m}^{3}\right)$ & th,m & thermodynamic to mechanical conversion \\
\hline $\mathrm{t}$ & time $(s)$ & $\mathrm{tt}$ & total to total \\
\hline$N_{\text {res }}$ & number of air storage tanks & ts & total to static \\
\hline $\mathrm{N}_{\mathrm{u}}$ & Nusselt number & s & isentropic \\
\hline $\mathrm{R}_{\mathrm{a}}$ & Rayleigh number & 0 & stagnation \\
\hline h & heat convection coefficient $\left(\mathrm{W} \cdot \mathrm{m}^{-2} \cdot \mathrm{K}^{-1}\right.$ ) & rem & remaining \\
\hline $\mathrm{H}$ & height $(\mathrm{m})$ & cold,TES & cold thermal energy storage \\
\hline $\mathrm{d}$ & thickness (m) & h,TES & hot thermal energy storage \\
\hline $\mathrm{D}$ & internal diameter $(\mathrm{m})$ & ch & charge \\
\hline$R_{t h}$ & thermal resistance $\left(\mathrm{W}^{-1} \cdot \mathrm{m} \cdot \mathrm{K}\right)$ & dis & discharge \\
\hline$Q_{s}$ & heat stored $(\mathrm{kWh})$ & a & air \\
\hline$\lambda$ & thermal conductivity $\left(\mathrm{W} \cdot \mathrm{m}^{-1} \cdot \mathrm{K}^{-1}\right)$ & $\mathrm{w}$ & water \\
\hline$Q_{r}$ & heat recuperated used on preheating of the compressed air & res & $\begin{array}{l}\text { reservoir } \\
\text { maximum pressure }\end{array}$ \\
\hline$Q_{\text {cool }}$ & cooling energy $(\mathrm{kWh})$ & $\begin{array}{l}\max \\
\min \end{array}$ & $\begin{array}{l}\text { maximum pressure } \\
\text { minimum pressure }\end{array}$ \\
\hline
\end{tabular}

to its high availability and starting reliability, environmentally benign, long life, low operation and maintenance costs $[13,15]$.

The working principle of A-CAES is as follows: during periods of surplus of renewable energy production or low energy demand, electrical energy is used to compress air, which is cooled to increase the energy density. The heat is stored in a thermal energy storage (TES). During periods of high demand, the compressed air is heated by TES and expanded in a turbine to produce the necessary electric energy.

At present, A-CAES has not been built at the utility scale whereas aboveground and underground pilot plants have been tested in China [16] and Switzerland [17,18], respectively. The pilot "TICC-500" designed by Wang et al. [16] achieved an efficiency of $22.6 \%$ with five compression stages driven by a motor of $350 \mathrm{~kW}$, three expansion stages connected to a generator of $500 \mathrm{~kW}$, air tanks with storage pressure ranging from $2.5 \mathrm{MPa}$ to $9.5 \mathrm{MPa}$, and pressurized water as thermal energy storage at $108{ }^{\circ} \mathrm{C}$. Geissbühler et al. [17] tested the air storage at a maximum storage pressure of 7 bars in an unused tunnel with different charging/discharging frequency, the calculated round trip efficiency based on variable compression and expansion ratio was within the range [63-74\%]. Becattini et al. [18] examined a combined sensible/latent TES formed by Al-Cu-Si alloy and packed bed of rocks with compressed air temperature at $566^{\circ} \mathrm{C}$, and their results showed a high TES efficiency ranging from $77 \%$ to $91 \%$.

The research and development on A-CAES have been very active in recent years. Budt et al. [12] carried out a literature review on CAES technologies and classified A-CAES according to the temperature level of TES. Previous researches demonstrated that this temperature level as well as the unavoidable heat at the exhaust of the expansion process have minor effect on system performances. Budt and Wolf [19] demonstrated that a low level of this temperature (below $200{ }^{\circ} \mathrm{C}$ ) keeps a high level of round-trip efficiency and overcomes technological problems related to high-temperature output of compressors. Zhang et al. [20] investigated the effect of thermal energy storage on the efficiency of A-CAES and found that a proportion of heat is left in TES which could be used to improve the efficiency of the system. In response, Zhou et al. [21] studied the effect of recovering the exhaust heat released from the output of the last stage turbine on the system efficiency of conventional CAES and A-CAES. The improvement on A-CAES is not significant because of the low value of the temperature of the exhaust flow.

Recent research investigations put the accent on the influence of the efficiency of turbines and compressors as well as the storage pressure on the system performances. Hartmann et al. [22] proved that the round trip efficiency of polytropic configuration is $10 \%$ lower than the isentropic configuration at 70\%. Grazzini and Milazzo [23] focused on the optimization of the design parameters of heat exchangers dedicated for A-CAES and they proposed in [24] an optimization strategy by using different arrangements of the compressors and expanders from parallel to series according to the pressure of the air reservoir. Mozayeni et al. [25] showed that the storage pressure has a significant effect on the amount of energy stored and found that the round-trip electric efficiency increases from $35 \%$ to $74 \%$ by increasing the efficiency of the compressors and turbines from 0.65 to 0.95 . In agreement with this, Luo et al. [26] developed a detailed model for A-CAES and focused on the system efficiency optimization via a parametric analysis. The main conclusion is that the system efficiency is mainly dominated by the isentropic efficiency of compressors and turbines and the heat transfer rate of heat exchangers. He et al. [27] studied the compression phase with variable pressure ratio and optimized the compression efficiency keeping it above $80 \%$ by varying the blade inlet angle and the rotational speed. Based on energy and exergy analysis, Szablowski et al. 
[28] found out, for a large scale system, that the major exergy destruction occurs in the compressors and turbines, and an important exergy loss is located at the throttling valve relaxing the air from 70 bars to 43 bars. Guo et al. [29] developed a dynamic model of ACAES operating between 4.2 MPa and 7 MPa taking into consideration part-load operations of compressors and turbines and demonstrated that those components are also the main responsible for the exergy destructions. According to design parameters, the system efficiency obtained by those studies ranged from $52 \%$ to $70 \%$.

In order to reduce the system losses, many researchers proposed innovative solutions. Houssainy et al. [30] proposed a patented novel hybrid high temperature thermal energy storage and low temperature A-CAES including a turbocharger unit that provides supplementary mass flow rate which contribute to decrease the storage pressure/volume and reducing the system cost. Kim [31] carried out an energy and exergy analysis of different configurations of CAES with adiabatic or quasi-isothermal compression and expansions, constant volume and constant pressure air storage. The results demonstrated that the configuration with constant pressure and isothermal process presents the higher performances. They proposed a patented constant-pressure compressed air energy storage (CAES) system combined with pumped hydro storage [32]. Mazloum et al. [33] proposed an innovative constant isobaric A-CAES including multistage adiabatic compression and expansion which achieved a round trip electrical efficiency of $53.6 \%$.

Previously, it has been demonstrated that CAES is adaptable to produce heating and cooling energy [6-10,34,35], hence the trigenerative compressed air energy storage T-CAES has been introduced. Many configurations have been proposed, which differ according to the manner in which the heat of compression is used. Facci et al. [6], Lv et al. [7], Liu and Wang [8] and Arabkoohsar et al. [34] devoted the heat produced during the charge phase for heating purposes while the electricity and the cooling energy are generated in the discharge phase. On the other hand, Jannelli et al. [9], Li et al. [10] and Han and Guo [35] suggested their configurations on the base of using an amount of heat stored during the expansion to increase the electrical efficiency while keeping the possibility to produce cooling and electrical energy.

With regards to experimental setup for T-CAES, Venkataramani et al. [36] constructed an experimental setup composed of a wind turbine $(3.2 \mathrm{~kW})$, a scroll compressor and expander and a reservoir (capacity of $400 \mathrm{~L}$ and maximum pressure of 8 bars). An investigation has been made on the effect of the discharge mass flow rate on the round trip efficiency, which achieved its best value of $22.02 \%$ with the highest mass flowrate. Cheayb et al. [37] used an experimental bench installed at IMT Atlantique, France. The experimental pilot is composed of multi-stage compressor driven by a motor of $3.17 \mathrm{~kW}$, an air reservoir having a capacity of $300 \mathrm{~L}$ and a maximum pressure of 310 bars and an air motor. The model results were found in good agreement with the experimental results with a maximum error of $13.2 \%$. Besides, the two latter studies stressed on the importance of the cogeneration in improving the round trip efficiency of the system.

The studies on T-CAES focused on introducing its concept, demonstrating its adaptability to specific applications and also on the modeling and optimization aspects. The proposed systems distinct in terms of their configuration and the choice of design parameters so that the resulted system efficiency was widely different varying from $30 \%$ to $76.3 \%$. Facci et al. [6] introduced a configuration with variable compression and expansion pressure ratio and proved the compatibility of the system with small size civil applications by means of satisfying peak shaving, heating and cooling demand. They investigated the effect of the design parameters on the efficiencies of the system such as the number of compression and expansion stages, turbines and compressors efficiency, maximum storage and expansion pressures. Values around $30 \%$ and $50 \%$ respectively were found for electric efficiency and exergy efficiency. Apart from that, Janelli et al. [9] proposed a configuration of $3.17 \mathrm{~kW}$ input and $1.25 \mathrm{~kW}$ output power with a maximum storage pressure of 35 bars and input expansion pressure of 25 bars and developed a design methodology of the storage system by applying it on a small scale stand-alone power station with photovoltaic energy production. The storage system has a round trip electric efficiency equal to $57 \%$ with a contribution on satisfying the cooling demand. Minutillo et al. [38] optimized the latter configuration considering it in different climate zones. Their results highlighted that the best performances are achieved by choosing both the lowest average pressure and the highest operating pressure range of the air tank. Liu and Wang [8] demonstrated that the coefficient of performance of the CAES system is improved by the cogeneration of heat and cold in the range of $20-30 \%$ depending on the values of the expansion ratio, the maximum storage pressure and the polytropic coefficient of the expanders. Lv et al. [7] applied a theoretical thermodynamic model on a T-CAES configuration with variable compression and expansion ratios and a low maximum storage pressure of 15 bars. The system was applied for electrical energy peak load shifting in a hotel. The results showed a high value of efficiency (76.3\%) and an annual monetary cost saving of about $53.9 \%$. Li et al. [10] introduced the comprehensive efficiency index to evaluate the T-CAES and investigated a configuration of the system for load shifting and for meeting the cooling and heating demands of an office building. The overall comprehensive efficiency achieved was high in winter months at $50 \%$ and lower in summer months at $30 \%$. Arabkoohsar et al. [34] demonstrated the potential of this system to support district heating and cooling and reserve services in electricity market for a typical large-scale application. The system was designed with different arrangement (series or parallel) of compressors and expanders. The values of power-to power, power-to-cooling and power-toheat efficiencies of this system were $30.6 \%, 32.3 \%$ and $92.4 \%$ respectively. Han and Guo [35] derived a T-CAES configuration from the ACAES and focused on optimizing the system by operating the expanders under variable pressure.

Previous optimization studies on the A-CAES and T-CAES identified different optimization opportunities such as varying the number of compression/expansion stages, increasing the effectiveness of heat exchangers and changing the storage pressure and other parameters stated above. Authors focused on one or more aspects and investigated the potential performance improvement. However, they overlooked or not clearly addressed the relations between the design parameters of the equipment. For instance, when the number of compression stages is changed the number of expansion stages was kept constant and when the water mass flow rate of intercooling heat exchangers HEX is changed (which changes the thermal energy storage temperature) the flow of the preheating HEX is fixed. Another limitation that could be highlighted in some studies when considering a variable pressure ratio is that the thermal energy storage is inadequately correlated to other compounds. This leads to an inaccurate estimation of the efficiency improvement.

In addition, the system was evaluated based on one or many evaluation criteria separately without taking into account most of them at the same time. As an example, when the round-trip efficiency was concerned the energy density and other parameters reflecting economic criteria were often discounted. Besides for the T-CAES, the technological aspects and technical constraints were often ignored in the modeling and simulation studies. This explains the wide range of choices of simulation parameters and the results found in the literature, misleading to have an accurate assessment of the system.

The objective of this study is to derive an optimal design guideline of the trigenerative compressed air energy storage based on an accurate thermodynamic model and parametric optimization, focusing at the same time on all interdependent design parameters of equipment and paying attention to the majority of assessment criteria at once. The contributions and novelties of this paper turn out as follows:

- The developed thermodynamic model accounts for technological and technical issues, pays a particular attention to interrelation between components especially heat exchangers integration as well 
as temperature levels of the thermal energy storage tanks. Besides, it appeals to the experimentally validated model of air side components published by Cheayb et al. [37].

- The parametric optimization focuses on the mutual effect of the design parameters in the case where the choice of one of them is conditional on others. In addition, the optimal number of expansions stages is derived and the effect of the thermal of energy storage is quantified for the first time. Indeed, no similar approach could be encountered in the literature.

- The study applies various criteria used to assess the energy storage technologies such as energy density, heat exchanger footprints, round trip electric efficiency and the comprehensive efficiency in the optimization of the T-CAES.

The entire structure is arranged as follows: Section 2 presents the methodology. Section 2.1 illustrates the proposed configuration of small-scale T-CAES based on the maximization of its electric efficiency. Sections 2.2 and 2.3 explain the thermodynamic model and the optimization procedure. The discussion of the results and the conclusions are carried out in Sections 3 and 4, respectively.

\section{Methodology}

\subsection{System description}

Fig. 1 shows the schematic diagram of the novel trigeneration system proposed in this paper. Fig. 2 presents the schematic of the last expansion stage and illustrates the temperature levels of air and heat transfer medium. The proposed concept derives from A-CAES with the difference being it enables producing heating and cooling energy. As well as A-CAES, during the charge phase ambient air is compressed via multistage compressors. The compressed air is cooled after each compression stage in a heat exchanger (HEX) by thermal energy storage medium (Fig. 1). Volumetric compressors are the most suitable for small-scale applications of CAES as reported by Cheayb et al. [37] so that they are selected in this study.

Regarding the thermal energy storage medium (TES), this study adopted the approach of low-temperature A-CAES presented by Budt and Wolf [19] where the temperature level of TES is below $200{ }^{\circ} \mathrm{C}$. It is known that phase change material could be used in favor of high energy density and constant storage temperature. However, in order to offer a flexibility in control and reduce the system cost, sensible heat storage is preferred. Among heat transfer medium such as thermal oil $[9,10]$, water [23] or Therminol 66 [35], pressurized water remains adequate for our application because of the low cost, the high thermal capacity and conductivity and being environmental friendly [12,26].

In order to achieve a high energy recuperation rate, the counterflow heat exchangers remains the best choice. On the other hand, shell and tube HEX exhibit a high design flexibility for different values of heat capacity and mass flowrates, high adaptability to high values of pressure and temperature [39]. By combining the advantages of these two types of HEX, a shell and tube heat exchanger with one shell and tubes pass and counter flow arrangement is chosen in the present study.

In the discharge phase, as shown in Fig. 1, the air pressure is reduced by a throttling valve (TV) in order to be compatible with the expansion machinery and to ensure a high energy density of the air stored at constant volume. Existing small scale pilot scale applications rely on volumetric expanders (see $[8,37]$ ). These later are considered as an ideal choice for small-scale CAES because of its low costs and low operational speed rotation [40]. In the other hand, existing volumetric expanders ratios are limited between 8 and 14 for piston expanders and 5 for scroll type as reported by Lemort et al. [41]. However, it is well known that a low expansion ratio lowers the electric efficiency of the system $[8,37]$, so the expansion machine should be designed to handle high input pressure. Recently, the Deprag company in collaboration with the University of Applied Science Amberg-Weiden (Germany) [42] developed a micro axial turbine which could work with an input pressure going to 25 bars. Thus, the first expansion stages are selected as axial turbines and the last stage as an air piston motor (AM) as an improvement for the previous study of Cheayb et al. [37] (see the discharge phase components in Fig. 1).

Since the preheating of air before expansion increases the round-trip efficiency, the heat stored should be exploited at the highest possible level. Consequently, when the cooling energy is needed it can be deduced from the last stage (see Figs. 1 and 2) and the heat is deployed in other stages (Fig. 1). Otherwise, the air is heated before all the expansion stages.

The analysis below highlights the identification of two design approaches, which lead to consider two configurations, as shown in Fig. 2:

- In the first configuration: the aim is to simplify the design and use the water temperature of cold TES directly in the charge phase so that the cold TES temperature should be as low as possible (close to ambient temperature) (see Fig. 2 left). Consequently, the output temperature of each turbine must be close to the ambient temperature and the cooling is achieved by releasing the outlet air of

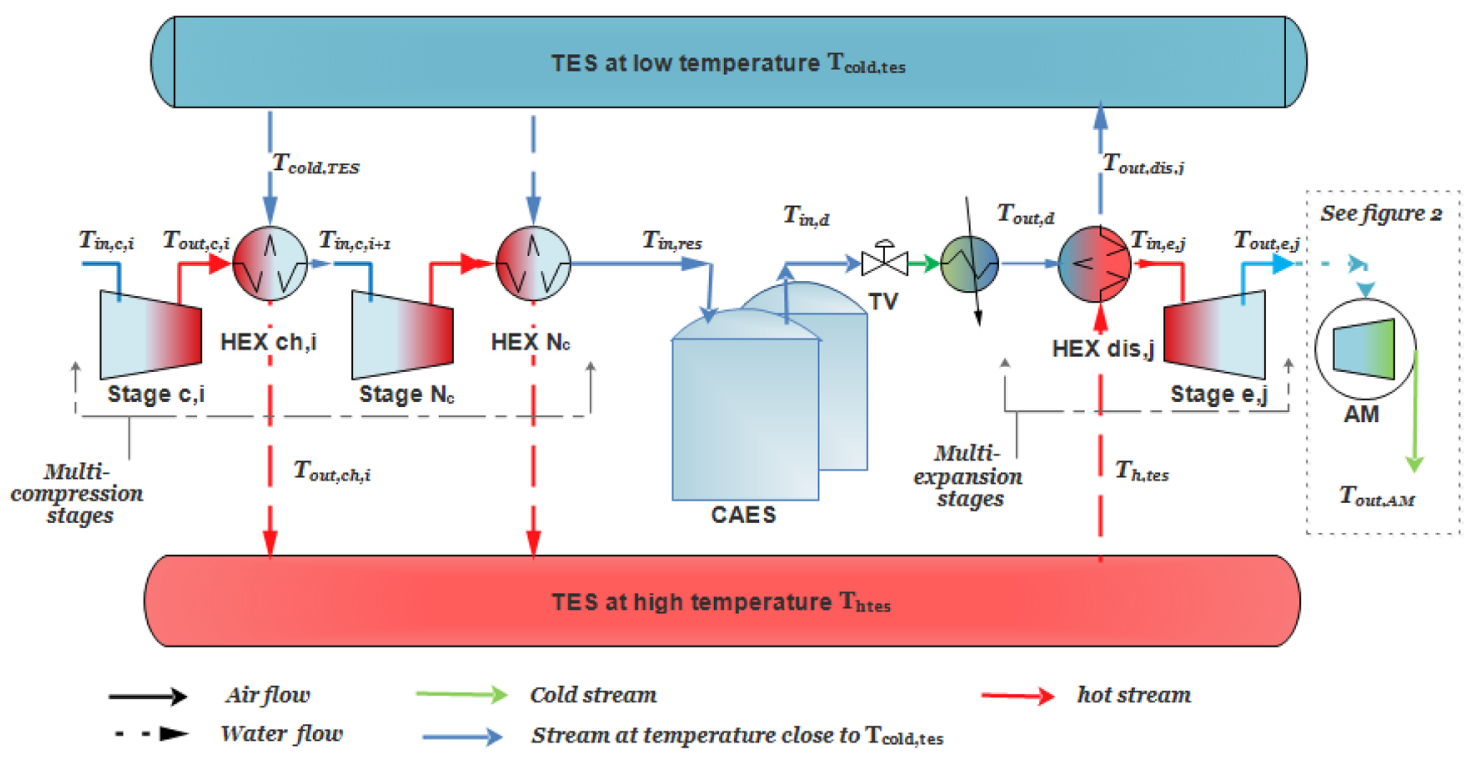

Fig. 1. Schematic diagram of the proposed trigenerative compressed air energy system with the main notations. 


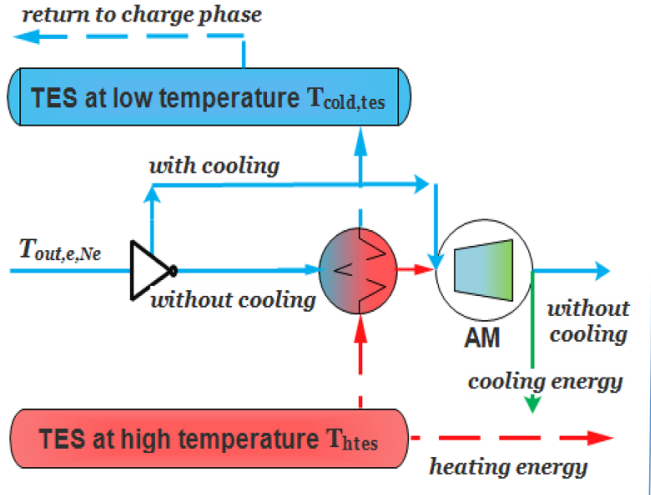

Temperature close to $T_{a m b}$

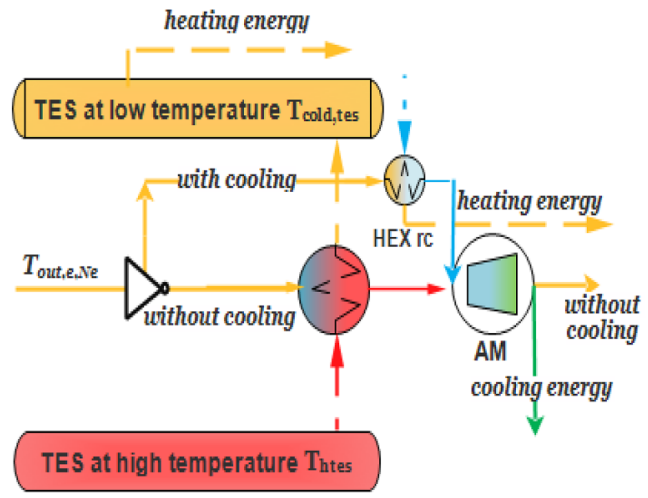

Temperature between $T_{\text {amb }}$ and $T_{\text {htes }}$

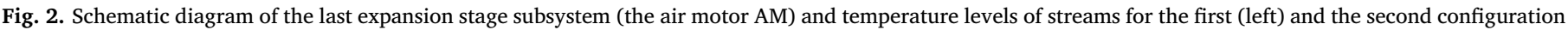
(right). (For interpretation of the references to color in this figure legend, the reader is referred to the web version of this article.)

turbines directly at the input of the air motor. This can be achieved by minimizing the water mass flow rate in the preheating heat exchangers so that the remaining water in hot TES tank is used directly for heating purposes (further explications can be found in Appendix 2 and Section 2.3).

- In the second configuration: the goal is to maximize the system electric efficiency by maximizing the air preheating. The air input temperature should be as high as possible, close to the hot TES temperature. As a result, the output temperature of each expansion stage would be higher than the ambient temperature (see Fig. 2 right), leading to adding a cooling HEX just before the AM (nominated by HEXrc in Fig. 2 right) to produce cooling energy when needed. This design concept induces a high value of the water temperature at the outlet of the HEX (orange colors in Fig. 2 right), which is used to satisfy the heating demand. Furthermore, as explained later in Section 2.2.3, there will be no water remaining in the hot-temperature reservoir of TES.

\subsection{Thermodynamic model of the T-CAES system}

The air-side components model developed by Cheayb et al. [37] which is validated experimentally - is used. The useful equations of this previous model are summarized in Appendix 3. Some improvements such as pressure losses and the model of heat exchangers HEX, air turbines and TES are added. In this section, only the complementary equations to the previous study [37] are presented below.

The model is based on the following hypotheses:

$>$ Air is considered as an ideal gas.

$\triangleright$ Pressure losses in the pipes are negligible.

$>$ It can be noticed from the tables giving the thermal properties of pressurized water that the effect of temperature on the heat capacity may be ignored.

$>$ Since operating pressure of expansion is much lower than of compression phase and pressure losses in HEX are proportional to the operating pressure as shown later in Eq. (2), the pressure losses in HEX of discharge phase are neglected compared with the losses in HEX of discharge phase.

$>$ Since there is no data concerning the variation of the polytropic coefficient of the air motor as a function of its input temperature, it is considered constant at 1.1 [37].

$>$ Since the temperature output of the throttling valve varies with the pressure of the compressed air [37], a dynamic model is needed to account these temperature variations, which is beyond the scope of this study. In order to deal with this issue, it was assumed that the heat exchanger installed after the throttling valve is able to maintain the temperature input of the first preheating heat exchanger $T_{i n, e, 1}$ at the ambient temperature. Besides, the associated cooling potential of this heat exchanger is not taken into account.

$>$ The temperature of the cold TES reservoir in the charge phase is at the ambient temperature. It is basically saying that: in the first configuration, the water at $T_{\text {cold, TES }}$ (which is slowly higher than the ambient temperature) achieved the room temperature just at the beginning of the charge phase by losing its small amount of heat to the environment. In the second configuration, all the heating energy is used so that the temperature of water supply of the cold TES reservoir is at the room temperature.

\subsubsection{Modeling of compressors and air reservoirs}

The calculations of temperatures input and output of each stage, the mass flow rate and the thermodynamic model of air stored in the reservoir are explained in details in the former paper [37] and summed up in Appendix A3. Firstly, the optimal distribution of compression ratio of each stage $\beta_{c, i}$ is symmetrical [43], so that:

$\beta_{c, \text { optimal }}=\left(\frac{P_{\text {in, res }}}{P_{\text {atm }}}\right)^{1 / N_{c}}$

Pressure losses in HEX are included in this paper as an improvement of the previous model [37]. An accurate account of these losses $\Delta P_{l}$ depends on the mass flowrate and design parameters of HEX, which is an advanced task. Herein, the approximation formula (2) of $\Delta P_{l}$ for each HEX of intercoolers reported by Jubeh and Najjar [44] and Liu and Wang [8] is used.

$\Delta P_{l, c, i}=\frac{0.0083 \varepsilon_{c, i}}{1-\varepsilon_{c, i}} P_{o u t, c, i}=\frac{0.0083 \varepsilon_{c, i}}{1-\varepsilon_{c, i}} \beta_{c, o p t i m a l}^{i} . P_{a t m}$

The required output pressure of each compression stage used to compensate the pressure losses $\Delta P_{l, c, i}$ is shown in Eq. (3) and the actual compression ratio of each stage $\beta_{c, i}$ is calculated by Eq. (4).

$P_{\text {out }, c, i}=\beta_{c, \text { optimal }}{ }^{i} \cdot P_{\text {atm }}+\Delta P_{l, c, i}$

$\beta_{c, i}=\frac{P_{\text {out }, c, i}}{\beta_{c}{ }^{i-1} \cdot P_{\text {atm }}}$

\subsubsection{Modeling of turbines and air motor}

Throughout the turbine, the thermodynamic energy of compressed air expressed by its enthalpy is transformed to kinematic energy in the stator, then to mechanical energy by the rotor. It is known that heat transfer is negligible in turbomachinery and the ideal process corresponds to an isentropic one, ideal power is written as: 
$\dot{W}_{e, \text { ideal }}=\dot{m}_{e} \cdot\left(h_{0, \text { in }}-h_{0 s, \text { out }}\right)=\dot{m}_{e} \cdot C_{p, a} \cdot T_{0 s, \text { in }, e} \cdot\left(1-\left(\frac{P_{0, \text { in }, e}}{P_{0, \text { out }, e}}\right)^{1-\gamma / \gamma}\right)$

where $T_{0}$ and $P_{0}$ are the stagnation temperature and pressure respectively and the index s refers to isentropic transformation.

Due to irreversibility induced by internal heat, the output temperature is actually higher than $T_{0 s \text {, out }}$, thus real power is indeed:

$\dot{W}_{e, \text { real }}=\dot{m}_{e}\left(h_{0, \text { in }}-h_{0, \text { out }}\right)=\dot{m}_{e} C_{p, a}\left(T_{0, \text { in }, e}-T_{0, \text { out }, e}\right)$

The ratio between the real and ideal work stands for the thermodynamic efficiency. However, the exit fluid velocity of the rotor is not at zero and the associated kinematic energy (named exhaust loss) shouldn't be ignored so that the terms total to total efficiency $\eta_{t t}$ and total to static efficiency $\eta_{t s}$ have been employed [45]. The former Eq. (5) does not include the kinematic energy whereas it is considered by the latter.

Owning that the kinematic energy can be converted in the subsequent turbine stage or the air motor, $\eta_{t t}$ is considered in this study, hence:

$\eta_{t t}=\frac{\left(T_{0, \text { in }, e}-T_{0, \text { out }, e}\right)}{T_{0 s, \text { in }, e} \cdot\left(1-\left(\frac{P_{0, \text { in }, e}}{P_{0, \text { out }, e}}\right)^{1-\gamma / \gamma}\right)}$

$\eta_{t t}$ is classically determined according to the two dimensionless parameters flow coefficients and stage load [45], which vary depending on design parameters and operation parameters (pressure ratio and flow rate). Performance curves can be found in text books, nonetheless those curves are developed using experimental tests on common and commercialized turbines at medium or large scale $[45,46]$.

In this study, the turbine used is recently developed and it is difficult to account for the performance characteristics. Notwithstanding, a value of $57 \%$ for the total to static efficiency is provided by the designer in which the compressed air is the working fluid and the expansion ratio is 10 [47]. This value was assumed in this study and considered as constant independently of operating conditions (pressure ratio, flow rate). At the same time, exhaust losses in turbines are estimated at around $3 \%$ to $5 \%$ of total losses [45], so that $\eta_{t t}$ was deducted from $\eta_{t s}$, equal to $1.05 \eta_{t s}$.

To conclude, the output temperature and electric power are derived from Eqs. (5)-(7) as follows:

$T_{o u t, e, j}=T_{i n, e, j}-\eta_{t t} . T_{i n, e, j}\left(1-\beta_{e, j}{ }^{1-\gamma / \gamma}\right)$

where $\beta_{e}$ is the expansion ratio of each expansion stage:

$\beta_{e, j}=\frac{P_{\text {in }, e, j}}{P_{\text {out }, e, j}}={\frac{P_{\min }}{P_{\text {in }, A M}}}^{1 / N_{e}}$

$\dot{W}_{e}=\eta_{e l, e} \sum_{j=1}^{j=N_{e}} \eta_{m, e} \eta_{t t} \dot{m}_{e} C_{p, a}\left(T_{i n, e, j}-T_{o u t, e, j}\right)$

$\eta_{m, e}$ is the mechanical conversion efficiency estimated to $95 \%$ for small scales turbines, and $\eta_{e l, e}$ is the electric efficiency of the generator.

For the second configuration, the temperature input of each stage is calculated by:

$T_{i n, e, j}=T_{h, T E S, d i s}-$ Pinch $_{e}$

The relation between the pinch point temperature difference Pinch and HEX effectiveness is derived in Appendix 1. It is expressed by:

Pinch $_{e}=\left(1-\varepsilon_{e}\right)\left(T_{h, T E S, \text { dis }}-T_{\text {out }, e, j-1}\right)$

As for the air motor, for more details, the reader can refer to reference [37].

It is important to figure out that the number of expansion stages $N_{e}$ play a key role in the design of T-CAES (note that $N_{e}$ denotes the number of expansion stages without the air motor because AM was devoted for cooling purposes). With this intention, let us consider the second configuration: for an imposed value of the temperature of TES, the input temperature of each expansion stage $N_{e}$ is related to $T_{h, T E S \text {, }}$ dis and the effectiveness of HEX (Eqs. (10) and (11)). A lower number of expansion stages $N_{e}$ results in a decrease of the output temperature and furthermore to decrease the electric efficiency .It can be easily seen that there is a critical number of $N_{e}$ (called $N_{e, \text { critical }}$ ) from which the output temperature of each stage become higher than the ambient temperature.

Taking into account the first configuration, at this value of $N_{e \text {, critical }}$ the input temperature of each expansion stage should be lowered to achieve the design condition of $T_{\text {out }, e, i}=T_{a m b}$. Increasing $N_{e}$ beyond $N_{\text {critical }}$ means a further decrease of the input temperature of each stage and consequently the electric efficiency. As a conclusion, the optimal number of expansion stages $N_{e, \text { optimal }}=N_{e, \text { crtical }}$.

It is true that in the second configuration, the electric efficiency may increase if $N_{e}>N_{e}$, crtical. However, it can be noticed from the results of the previous study of Luo et al. [26] that the global electric efficiency $\eta_{e}$ increases slightly above a value of $N_{e}$ corresponding to $T_{\text {out }, e, i}$ close to $T_{a m b}$. Moreover, many simulations were carried out and proved the latter achievement. Besides, it is more valuable to compare the two configurations for the same number of stages. The flow diagram of the method used to determine $N_{e}$, optimal is presented in Fig. 3 . It is found by an iteration procedure by increasing the value of $N_{e}$, and calculating the output temperature of turbine stages $T_{\text {out }, e, i}$. The iteration stops as soon as $T_{\text {out, e, } i}$ becomes higher than $T_{\text {amb }}$.

Now, $N_{e, \text { optimal }}$ and the temperature input and output of turbines for the second configuration are known. By contrast, in the first configuration, the temperature input of each stage should satisfy the condition of $T_{\text {out }, e, j}=T_{a m b}$.As a result, $T_{i n, e, j}$ could be expressed by using Eqs. (8a) and (8b) as:

$T_{i n, e, j}=\frac{T_{a m b}}{1-\eta_{t t} \cdot\left(1-{\frac{P_{i n, e, j}}{P_{\text {out }, e, j}}}^{1-\gamma / \gamma}\right)}$

\subsubsection{Modeling of heat exchangers and TES}

Typical input design parameters of HEX are mass flow, heat capacity and outlet temperatures of hot and cold fluids [39]. The number of transfer unit method NTU has been used, which is described subsequently. Further details and comprehensive information are presented in Appendix 1.

The main design characteristic of HEX is its effectiveness which is generally defined by Eqs. (13a) and (13b).

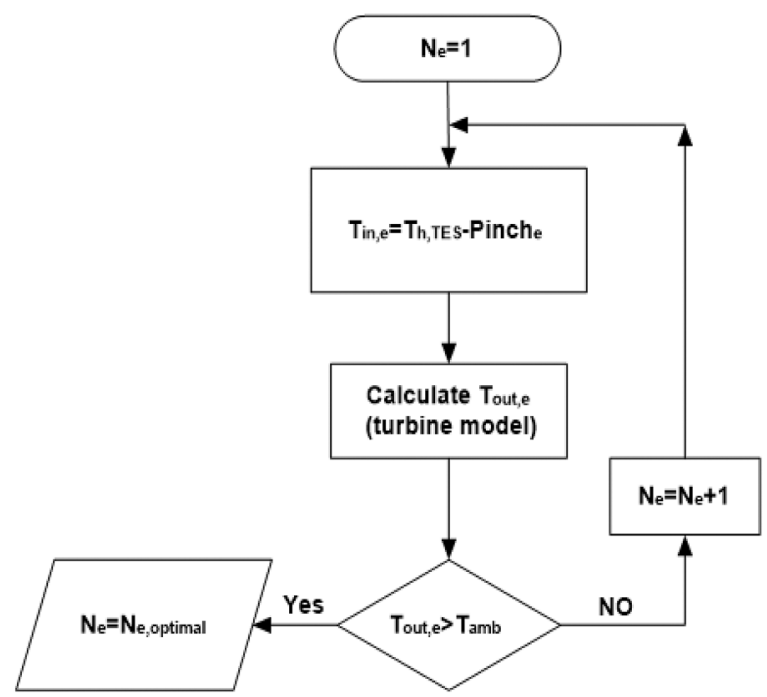

Fig. 3. Algorithm used to select the optimal number of expansion stages. 
$\varepsilon=\frac{C_{\text {hot }} \cdot\left(T_{\text {in }, \text { hot }}-T_{\text {out }, \text { hot }}\right)}{C_{\text {min }}\left(T_{\text {in,hot }}-T_{\text {in }, \text { cold }}\right)}$

or

$\varepsilon=\frac{C_{\text {cold }} \cdot\left(T_{\text {out }, \text { cold }}-T_{\text {in, cold }}\right)}{C_{\min }\left(T_{\text {in }, \text { hot }}-T_{\text {in }, \text { cold }}\right)}$

$C$ is the thermal capacity of the flow, which equals the product of the mass flow rate of the flow and its heat capacity.

The number of transfer unit NTU is a function of heat exchanger efficiency, flow arrangements, $C_{\min }$ to $C_{\max }$ ratio and HEX type (for example number of shell pass and tube passes, cross flow HEX) .NTU approach and relations for different types of HEX are reported in details in [48]. In this study, shell and tube HEX with one shell and tube pass and counter flow arrangements was considered, the corresponding NTU relations are shown in Eqs. (14a) and (14b):

for $z<1: \mathrm{NTU}=\frac{\ln \left(\frac{1-z \cdot \varepsilon_{j}}{1-\varepsilon_{j}}\right)}{\ln (1-z)}$

for $z=1: \mathrm{NTU}=\frac{\varepsilon_{j}}{1-\varepsilon_{j}}$

where $z=\frac{C_{\min }}{C_{\max }}$

Following the NTU method, the HEX footprint is expressed by:

$(U A)=N T U \cdot C_{\min }$

The charge phase is common to both configurations so the same model is used. During the charge phase, once $T_{h, T E S}$, ch is imposed, heat balance between air and water sides enables the calculation of water mass flow rate of each HEX as follow:

$\dot{m}_{w, c h, i}=\frac{C_{\min }\left(T_{i n, c, i}-T_{i n, c, i+1}\right)}{C_{p, w}\left(T_{h, T E S}-T_{\text {cold }, T E S}\right)}$

where $C_{\min }=\dot{m}_{a, c} . C_{p, a}$ and $C_{\max }=\dot{m}_{w, c h, i} \cdot C_{p, w}$ (see annex 1).

It should be noted that the maximum value of $T_{h}$, TES is to be chosen such as $C_{\min } \leq C_{\max }$, thus $T_{h}$, TES should satisfy the following condition:

$T_{h, T E S} \leq\left(T_{i n, c, i}-T_{i n, c, i+1}\right)+T_{\text {cold }, T E S}$

The total mass flow of water that can be stored at the temperature $T_{h, T E S}$ is the sum of the flows leaving HEX, the total mass of stored water and the necessary volume of the storage tank are expressed in Eqs. (18) and (19).

$m_{T E S}=\sum_{i=1}^{N_{c}} \dot{m}_{w, c h, i} \cdot t_{c h}$

$V_{\text {res }, T E S}=\frac{m_{T E S}}{\rho_{w}}$

In the end, the total thermal energy that could be stored could be computed from the air side or water side by Eq. (20).

$$
\begin{aligned}
Q_{s} & =\sum_{i=1}^{i=N c} \dot{m}_{c} \cdot C_{p, a} \cdot\left(T_{\text {out }, c, i}-T_{i n, c, i+1}\right) \cdot t_{c h} \\
& =\sum_{i=1}^{i=N c} \dot{m}_{w, c h, i} \cdot C_{p, w} \cdot\left(T_{\text {cold }, T E S}-T_{h, T E S}\right) \cdot t_{c h}
\end{aligned}
$$

During the storage process, it is obvious that the water mass is conserved, but the temperature of TES drops due to heat transfer with the environment. One can account this loss by integrating a model of the TES reservoir. However, it is supposed that the TES tank is sufficiently isolated to achieve a high thermal efficiency of $95 \%$ with a short storage period (range of hours). The thermal efficiency is defined as:
$\eta_{T E S}=\frac{m_{T E S} C_{p, w}\left(T_{h, T E S, d i s}-T_{a m b}\right)}{m_{T E S} C_{p, w}\left(T_{h, T E S}-T_{a m b}\right)}=\frac{T_{h, T E S, d i s}-T_{a m b}}{T_{h, T E S}-T_{a m b}}$

The temperature of TES in the discharge phase is calculated by:

$T_{h, T E S, d i s}=\eta_{T E S}\left(T_{h, T E S}-T_{a m b}\right)+T_{a m b}$

Heat loss is then:

$Q_{\text {loss }}=m_{T E S} C_{p, w}\left(T_{h, T E S}-T_{h, T E S, d i s}\right)$

Next, modifications were included in the model depending on the configuration of the discharge phase.

2.2.3.1. Equations of the discharge phase for the first configuration. In the discharge phase, for the first configuration the output temperature of water flow $T_{\text {out, dis, } j}$ in HEX is governed by its effectiveness or its pinch point temperature difference Pinch $_{e}$ as expressed by Eq. (24a), while the mass flow rate is determined by the heat balance between each flow of the $\operatorname{HEX}$ (Eq. (24b)).

$T_{\text {out }, \text { dis }, j}=T_{\text {out }, e, j-1}+$ Pinch $_{e}$

where the relation between Pinch $_{e}$ and the HEX effectiveness is shown in Eq. (A1.6).

$\dot{m}_{w, d i s, j}=\frac{C_{\max }\left(T_{\text {in }, e, j}-T_{\text {out }, e, j-1)}\right.}{C_{p, w}\left(T_{h, T E S, c h}-T_{\text {out }, \text { dis }, j}\right)}$

where $C_{\min }=\dot{m}_{w, d i s, j} . C_{p, w} \quad$ and $\quad C_{\max }=\dot{m}_{a, e} . C_{p, a}$ for the first configuration.

By applying the heat and mass balance, the accumulated mass of the outflow water of preheating HEX and its temperature, the remaining mass in high TES temperature tank and also the heating energy potential are presented on Eqs. (24c)-(24e).

$m_{\text {cold }, T E S}=\sum_{i=1}^{N_{e}+x} \dot{m}_{w, d i s, j} \cdot t_{d i s}$

$m_{\text {rem }, h, T E S}=m_{\text {heating }}=m_{T E S}-\sum_{i=1}^{N_{e}+\bar{x}} \dot{m}_{w, \text { dis }, j} . t_{\text {dis }}$

where: $\bar{x}=1$ if the cooling is activated, otherwise $\bar{x}=0$.

$Q_{\text {heat }, 1}=m_{\text {rem }, h, T E S} \cdot C_{p, w} \cdot\left(T_{h, T E S}-T_{a m b}\right)$

2.2.3.2. Equations of the discharge phase for the second configuration. For the second configuration, one can design the HEX such as the temperature variation in the air side is the same as the water side which decreases the temperature difference between the two sides and the required footprint. In order to minimize this latter, the maximum mass flow rate and the least possible temperature output of water flow should be chosen (see Fig. A2.1). This is achieved by pumping all the water of the hot temperature reservoir to the reservoir at low temperature. Consequently, the water mass flow is determined by applying the mass balance on TES (Eq. (25b)). The heat balance in the HEX enables the calculation of the output water temperature (Eq. (25a)).

$T_{\text {out }, \text { dis }, j}=T_{h, T E S, d i s}-\varepsilon_{e, j} \cdot \frac{C_{\text {min }}}{C_{\max }}\left(T_{h, T E S}-T_{\text {out }, e, j-1}\right)$

$\dot{m}_{w, d i s, j}=\frac{m_{T E S}}{\left(N_{e}+x\right) t_{d i s}}$

where: $x=0$ if the cooling is activated, otherwise $x=1$.

$C_{\text {min }}=\dot{m}_{a, e} . C_{p, a}$ and $C_{\max }=\dot{m}_{w, d i s, j} . C_{p, w}$ for the second configuration.

Returning to TES, as mentioned above:

- In the first configuration, an amount of water is remaining in the hot TES tank which is used for heating and the temperature return of 
preheating HEX approaches the ambient temperature.

- In the second one, the return temperature of TES is sufficiency high to be used for heating purposes and the reservoir at high temperature is fully empty by the end of the discharge phase.

$m_{\text {cold }, T E S}=m_{\text {heating }}=m_{h, T E S}$

$m_{\text {rem, }, T E S}=0$

$$
\begin{aligned}
Q_{\text {heat }, 2}= & m_{\text {cold }, T E S} \cdot C_{p, w} \cdot\left(T_{\text {cold }, T E S}-T_{a m b}\right) \\
& +x \cdot C_{\text {max }, \mathrm{Ne}+1}\left(T_{\text {out }, \text { dis }, \mathrm{Ne}+1}-T_{a m b}\right) \cdot t_{d i s}
\end{aligned}
$$

where the second term of the Eq. (25) accounts for the energy required in order to recool the outlet air of the last turbine stage before it is introduced in the air motor AM to produce cooling energy. This term will be void if the cooling energy is not activated.

It is important to note that $\dot{m}_{w, d i s, j}$ is sufficiently high to verify the design method based on $\dot{m}_{w, d i s, j} . C_{p, w} \geq \dot{m}_{a, e} . C_{p, a}$, say:

$\dot{m}_{w, d i s, j} \geq \frac{C_{\min }}{C_{p, w}}$

2.2.3.3. Equations of the cold TES for the first and second configurations. The temperature $T_{\text {cold, }}$ TES of the returning water can be calculated by applying energy balance as shown in Eq. (27).

$T_{\text {cold }, T E S}=\sum_{i=1}^{N_{e}+x} \frac{\dot{m}_{w, d i s, j} T_{o u t, d i s, j}}{m_{\text {cold }, T E S}} t_{\text {dis }}$

In the end, the thermal energy recuperated to preheat the air before expansion can be computed from the air side or water side by Eq. (28) and cooling energy is deduced by Eq. (29).

$$
\begin{aligned}
Q_{r} & =\sum_{i=1}^{i=N e+\bar{x}} \dot{m}_{e} \cdot C_{p, a} \cdot\left(T_{o u t, e, j-1}-T_{i n, e, j}\right) \cdot t_{d i s} \\
& =\sum_{i=1}^{i=N e+\bar{x}} \dot{m}_{w, d i s, j} \cdot C_{p, w} \cdot\left(T_{h, T E S}-T_{o u t, d i s, j}\right) \cdot t_{d i s}
\end{aligned}
$$

where $T_{\text {out }, e, o}$ is the temperature input of the first HEX.

$Q_{\text {cool }}=\bar{x} \cdot \dot{m}_{e} \cdot C_{p, a} \cdot\left(T_{a m b}-T_{o u t, A M}\right) \cdot t_{d i s}$

where: $\bar{x}=1$ if the cooling is activated, otherwise $\bar{x}=0$.

\subsection{Parametric study for the optimization of the T-CAES}

The optimization of energy systems can be conducted by using thermoeconomic analysis, multi-objective optimization or parametric study [49]. However, our system is recently proposed and the analysis via parametric study figures out the key drivers for the optimization of the performances of the T-CAES. This analysis starts by identifying the design parameters and dissect their effect on the performances of the system. In this section, the relevant parameters were retained from the thermodynamic model to reveal their impact on the evaluation criteria described below in Section 2.4.

Table 1 lists the base values of the fixed parameters used in our study. Herein, firstly, input power scale and reservoir volumes correspond to a small scale unit in accordance with Jannelli et al. [9] and the experimental pilot used by Cheayb et al. [37]. Secondly, the output temperature of the air motor should be upper than the minimum allowed temperature specified by the designer $\left(-20{ }^{\circ} \mathrm{C}\right.$ according to [50]). Owning that the minimum ambient temperature on which the cooling energy should be activated is $25{ }^{\circ} \mathrm{C}$, a simple calculation gives that an output temperature of air motor at $-20{ }^{\circ} \mathrm{C}$ corresponds to a pressure input of 6 bar (absolute value). The expansion mass flow rate at $0.0183 \mathrm{~kg} / \mathrm{s}$ corresponds to the maximum efficiency of the air motor at the fixed pressure [37], while at the same time it is ensured its adaptability to air turbines and to produce a total output power (ranging from $1.5 \mathrm{~kW}$ to $2 \mathrm{~kW}$ ) to meet the need of a small scale electric load. In the end, the values of the performance parameters of machinery such as efficiency were collected from available commercial data (where the highest values

\begin{tabular}{|c|c|c|}
\hline Fixed parameters & Value & Reference \\
\hline Ambient temperature $\left[{ }^{\circ} \mathrm{C}\right]$ & 30 & - \\
\hline Input power $[\mathrm{kW}]$ & 3.17 & [37] \\
\hline Polytropic coefficient of compressors & 1.25 & {$[37]$} \\
\hline Compressor mechanical efficiency & 0.9 & Average value of the range $(0.85 ; 0,95)[51]$ \\
\hline Motor electric efficiency & 0.9 & Premium motor efficiency [52] \\
\hline Total volume of 6 air storage reservoirs $\left[\mathrm{m}^{3}\right]$ & 0.29 & {$[37]$} \\
\hline Dimension of each air reservoir (height $\times$ diameter) $[\mathrm{m}]$ & $1.4 \times 0.21$ & {$[37]$} \\
\hline Storage time $[\mathrm{h}]$ & 5.5 & Time required to stabilize the temperature and pressure [37]. \\
\hline Thermal efficiency of TES & 0.95 & - \\
\hline Expansion mass flow $[\mathrm{kg} / \mathrm{s}]$ & 0.0183 & - \\
\hline Minimum pressure of compressed air [bar] & 25 & [47] \\
\hline Total to total efficiency of turbines & 0.63 & [47] \\
\hline Mechanical efficiency of turbines & 0.95 & [45] \\
\hline Generator electric efficiency & 0.9 & Like motors \\
\hline Minimum allowed temperature output of $\mathrm{AM}\left[{ }^{\circ} \mathrm{C}\right]$ & -20 & {$[50]$} \\
\hline Input pressure of $\mathrm{AM}$ (bar) & 6 & Analysis of AM data \\
\hline Polytropic coefficient of AM & 1.1 & [37] \\
\hline Thermodynamic to mechanical efficiency conversion of AM & 0.304 & [37] \\
\hline $\mathrm{COP}_{\text {heat pump }}($ heating mode) & 4 & [9] \\
\hline $\mathrm{COP}_{\text {heat pump }}$ (cooling mode) & 3 & [9] \\
\hline Varying parameters & & Value ranging \\
\hline Temperature of hot TES $\left[{ }^{\circ} \mathrm{C}\right]$ & & {$[70 ; 150]$} \\
\hline Effectiveness of HEX & & {$[0.65 ; 0.97]$} \\
\hline Maximum pressure of compressed air [bar] & & {$[30 ; 350]$} \\
\hline Number of compression stages & & {$[2 ; 7]$} \\
\hline
\end{tabular}
are taken) or from the estimated values in the literature.

Table 1

Fixed parameters and variable parameters of the parametric study. 
Table 1 also presents the design varying parameters and their ranges of variation. These parameters are varied one at a time or many at the same time to study their effects on the system performances. As an illustration, when the temperature of TES is varied the number of compression stages and HEX effectiveness are constant (the parameters are varied one at a time). On the other hand, when the number of compression stages is varied the effectiveness of HEX is constant, while the thermal energy storage temperature should be changed (many parameters are changing at the same time). Each case will be explained further in Section 3.

\subsection{Evaluation criteria}

It is recognized that each energy storage technology should be assessed based on different criteria such as: technical maturity, energy density, efficiency, cost and others criteria. All of them are well explained in details by Luo et al. [1] and Chen et al. [2]. Hence, the criteria which can be accounted for by the thermodynamic modeling are well established in this study and listed as follows:

Energy density $E_{d}\left(\mathrm{kWh} / \mathrm{m}^{3}\right)$ is defined by the amount of output energy provided per unit of volume as expressed by Eq. (30). This criterion is of crucial importance, as higher energy density requires a small volume which makes the system more compact and may reduce its cost.

$E_{d}=\frac{E_{\text {out }, e l, e}}{V_{\text {res }}}$

where $E_{\text {out, ele }}$ is the output electrical energy and is accounted by:

$E_{\text {out }, e l}=\dot{W}_{e l, e} \cdot t_{d i s}$

Round trip electrical efficiency or simply electrical efficiency: it is defined by the ratio of energy output to energy input.

$\eta_{e l}=\frac{E_{\text {out }, e l}}{E_{\text {in,el }}}=\frac{\dot{W}_{\text {el,e }} t_{\text {dis }}}{\dot{W}_{e l, c} t_{c h}}$

Since our system produces heating and cooling energy, the coefficient of performance defined by Eq. (33) accounts for these elements. By contrast, it is more appropriate to compare our system with other electrical energy storage technologies, so the comprehensive efficiency defined by Eq. (34) is used on which the cooling and heating energy are replaced by the equivalent electrical energy to produce the heating and cooling energy by a conventional heat pump (see [10] and [37] for further details).

$C O P_{g}=\frac{Q_{s}+Q_{\text {cool }}+E_{\text {out }, \text { el }}}{E_{\text {in,el }}}$

$\eta_{g}=\frac{\frac{Q_{\text {heat }}}{\operatorname{COP}_{\text {ref }, \text { heat }}}+\frac{Q_{\text {cool }}}{C O P_{\text {ref }, \text { cool }}}+E_{\text {out }, \text { el }}}{E_{\text {in, }, e l}}$

where $C O P_{\text {ref, heat }}$ and $C O P_{\text {ref, cool }}$ are the performance coefficients of conventional heat pump functioning on heating and cooling mode respectively.

The cost of the system is a vital criterion to be assessed. It begins with finding the characteristics of each component of the system including the number of compression and expansion stages, heat exchangers footprints, reservoir volume and operating pressures. All these parameters will be discussed for the sake of reducing the cost of the system. Note that the estimation of the cost of each component is beyond the scope of this article. Finally, the system is also assessed in term of the time of charge and discharge which have a useful practical significance.

To sum up the thermodynamic model and the evaluation criteria, Fig. 4 shows the block diagram of the T-CAES system model with the main input and output parameters. In previous studies $[6,10,26]$, optimization study via parametric analysis was made by varying one parameter and taking the others as default values. In our study, as mentioned earlier the mutual effects of the parameters are studied attempting to find optimal solutions for the design of the system. Using the method explained in the previous section, the effect of the parameters listed in Table 1 was evaluated by taking into consideration the impact of each parameter in others. Then, optimal solutions are derived and the two configurations are compared. The cooling energy was initially activated in all cases and then disabled to investigate its effect.

\section{Results and discussions}

\subsection{Effects of the temperature of the thermal energy storage}

The following parameters are fixed:

1 Number of compression stages $N_{c}=3$.

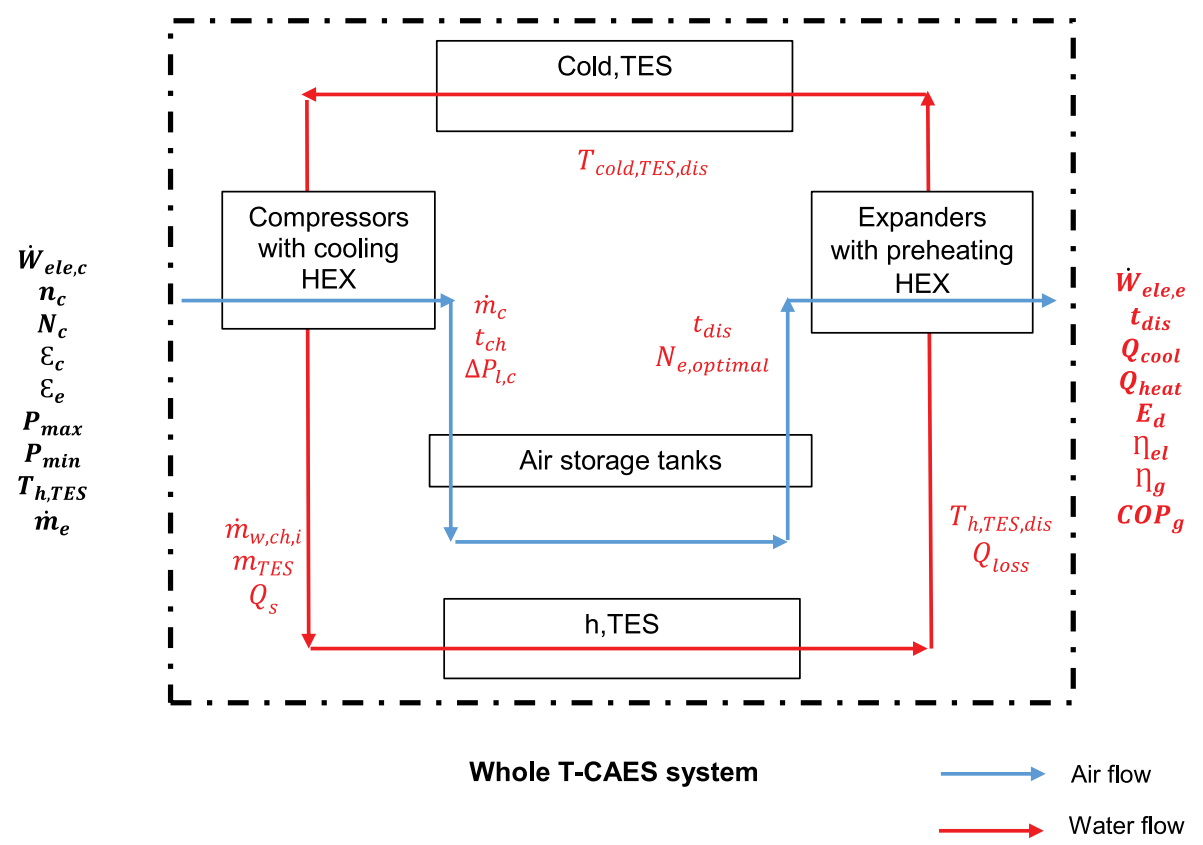

Fig. 4. Block diagram of the thermodynamic model of the whole T-CAES system with main input parameters (black) and output parameters (red). (For interpretation of the references to color in this figure legend, the reader is referred to the web version of this article.) 
2 Maximum pressure $P_{\max }=200$ bars.

3 The effectiveness of HEX : $\varepsilon_{c}=\varepsilon_{e}=0.85$.

The variation of electric and comprehensive efficiencies and also the optimal number of expansion stages, HEX footprints and finally the temperature of cold TES and the output temperature are shown in Fig. 5(a), (b) and (c) respectively.

In the discharge process, in order to satisfy the condition of the output temperature of the turbine close to the ambient temperature, a higher level of $T_{h}$ TES means a low number of expansion stages which decreases at a critical values of $T_{h}$, TES at $80^{\circ} \mathrm{C}$ and $130{ }^{\circ} \mathrm{C}$ (see Fig. 5(a)).

According to Fig. 5(a), in the second configuration, the electrical efficiency and the comprehensive efficiency increase continuously a little due to the fact that the input temperature of turbines increases with $T_{h}$, TES. In the other hand, in the first configuration those efficiencies raises only as from the critical values of $T_{h, T E S}$ (corresponding to a change of $N_{e}$ ).the maximum increase of the electrical efficiency and comprehensive efficiency is about $8.5 \%$ and $3.6 \%$ respectively of its initial values at $14.6 \%$ and $26 \%$. These values have proved that the cogeneration option increases the global efficiency (by about $11.4 \%$ in this case) and the temperature of TES have a minor impact on the electric efficiency as stated by Wolf and Budt [19].

Before analyzing the required HEX footprints, it is known that the total footprint of a number of HEX is governed by the logarithmic mean temperature difference (LMTD) of each HEX and obviously the number of HEX.

In the charge process, once the temperature of thermal energy storage is changed while keeping the HEX effectiveness as constant, the water mass flow rate should decrease and the logarithmic mean temperature difference (LMTD) of each HEX decreases. As a result, the total footprint of the three intercooling HEX in compression phase increases (see Fig. 5(b)).
In the discharge phase, it can be observed also from Fig. 5(b) that the general trend of the discharge phase HEX footprint decreases as $T_{h}$, $T E S$ increases due to the fact that the number of expansion stages decreases. However, a further inspection says that at the critical values of $T_{h}$, TES the footprint has its maximum value for the first configuration and its minimum values for the second configuration. Afterwards, the footprint of the first configuration decreases significantly (of an average value of $3.15 \mathrm{~W} /{ }^{\circ} \mathrm{C}$ ) which results from the increasing the LMTD of each HEX exchanger, whereas the footprint of the second configuration increases slowly (of an average value of $0.39 \mathrm{~W} /{ }^{\circ} \mathrm{C}$ ) which is linked also for the little increase of the LMTD.

In totality, the total footprint of all the HEX is mainly influenced by the HEX of the discharge phase (see the trend of the red line in Fig. 5(b)). It takes its minimum values always in the first configuration due the additional recooling HEX in the second configuration. The minimal possible of $103 \mathrm{~W} / \mathrm{K}$ was achieved at $T_{h, T E S}=120^{\circ} \mathrm{C}$ in the first configuration, while the values were $\left(130^{\circ} \mathrm{C} ; 215 \mathrm{~W} / \mathrm{K}\right)$ for the second configuration.

From Fig. 5(c), it can be seen that the temperature of cold TES is almost constant at $10{ }^{\circ} \mathrm{C}$ higher than the ambient temperature which is linked to the pinch point temperature difference Pinch $_{e}$. By contrast, in the second configuration, since Pinch $_{e}$ is related to $T_{h, T E S}, T_{\text {cold, TES }}$ increases almost linearly versus $T_{h}$, TES for a fixed number of expansion stages and presents discontinuities with varying $N_{e}$. Its value is always above $60{ }^{\circ} \mathrm{C}$ which is suitable for heating purposes.

Finally, as can be predicted from the design methodology, the output temperature of air motor is constant at -15 (where the ambient temperature is $30^{\circ} \mathrm{C}$ ) for the first configuration but it is a little higher in the range of $[-12 ;-15.2]$ in the second configuration which is attributed to the effectiveness of the recooling HEX. It should be noted that the heating and cooling energy shows a very little difference between the 2 configurations (data are not shown because of the minor effect).

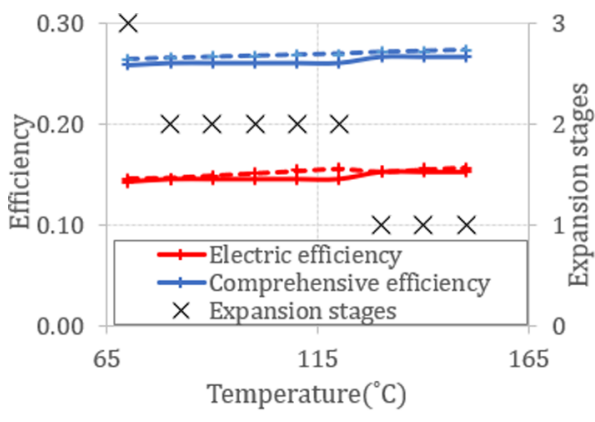

a. T-CAES efficiencies (left axis) and the optimal number of expansion stages (right axis) as a function of the temperature of TES.

(Solid line for first configuration and dashed line for the second)

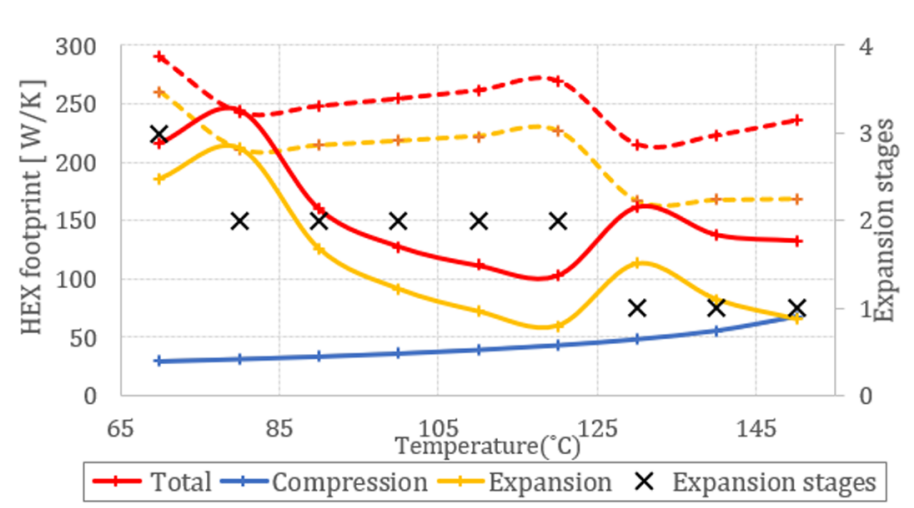

b. Required HEX footprints (left axis) and the number of expansion stages (right axis) as a function of the hot

temperature of TES (solid line for first configuration and dashed line for the second).
tequired c. The temperature of AM and of the cold TES as a function of the hot temperature of TES.
Fig. 5. (a) T-CAES efficiencies (left axis) and the optimal number of expansion stages (right axis) as a function of the temperature of TES (Solid line for first configuration and dashed line for the second). (b) Required HEX footprints (left axis) and the number of expansion stages (right axis) as a function of the hot temperature of TES (solid line for first configuration and dashed line for the second). (c) The temperature of $\mathrm{AM}$ and of the cold TES as a function of the hot temperature of TES. (For interpretation of the references to color in this figure legend, the reader is referred to the web version of this article.)

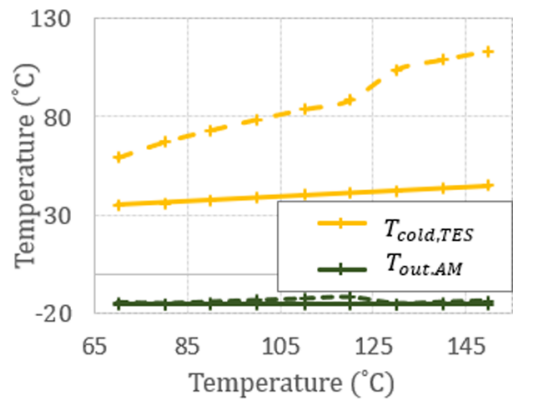


To summarize, generally speaking, an increase in the temperature of TES results in a decrease of the required expansion stages and the required HEX footprint but a slight increase of the electric and comprehensive efficiency. Besides, there are critical values of $T_{h}$, TES to be avoided $\left(80^{\circ} \mathrm{C}\right.$ and $130{ }^{\circ} \mathrm{C}$ for the first configuration) in order to reduce the HEX footprints without a much decrease of the efficiencies of the system. Eventually, the first configuration is simpler and better from an economical point of view (based on HEX footprints).

\subsection{Effects of the number of compression stages}

The effect of this parameter is studied in the literature taking into account a constant temperature of TES [6] or constant mass flow rate of intercooling HEX [26] and with a constant number of expansion stages. It is important to reinforce the analysis by integrating a reasonable choice of $T_{h}$, TES and varying the number of expansion stages. In this work, this temperature is varied according to the results obtained in the Section 3.1, it is chosen in order to reduce the system complexity (number of expansion stages and total HEX footprints) and simplify our analysis. Consequently, $T_{h}$, TES was selected the maximum possible value (in other words $C_{\min }=C_{\max }$ for intercooling HEX) which matches these objectives (see Fig. 5(b)).

The other parameters were fixed as follows:

1 Maximum pressure $P_{\max }=200$ bars.

2 The effectiveness of HEX : $\varepsilon_{c}=\varepsilon_{e}=0.85$.

As evident from Fig. 6(a) the rise of the number of compression stages implies an increase of the expansion stages going from critical values (passing from three compression stages to two and from 6 to 7), meanwhile the temperature of TES is reduced which is a consequence of the decline of the temperature output of each compression stage.
Fig. 6(c) displays the variation of the ratio of discharge time to charge time and the heat stored as a function of the number of compression stages. It is known from the literature that a higher number of $N_{c}$ increases the compression efficiency which means a reduce of the time of charge for a fixed electric power input, thus it can be seen that the ratio $t_{\text {dis }} / t_{c h}$ augment with $N_{c}$ substantially (around 19\%) at the beginning (passing from 2 to 4 stages) and slightly (about 3\%) afterwards. Turning to the heat stored, $N_{c}$ has a marginal effect on it. Similarly, heating and cooling energy hardly varies (data are not shown here).

Fig. 6(b) reports the variation of the efficiencies of the system. Since the time of charge is increased, the electric and comprehensive efficiencies share the same behaviors as the $t_{d i s} / t_{c h}$ ratio, with a little increase when the number of compression stages are above three or four. These variations are consistent with that of Luo et al. [26] and Facci et al. [6] with a difference on the values of the electrical efficiency.

The required HEX footprints are given in Fig. 6(d). Generally speaking, the rise of compression stages, as well as expansion stages and HEX are behind the increase of the total footprints. Adding that the required footprints of the second configuration are always higher than the first one. Nevertheless, some exceptional cases occur, for instance, the total footprint for the first configuration is slightly lower when $N_{c}$ increases from 6 to 7 which can be attributed to a higher LMTD of HEX in the discharge phase.

To conclude, there is an optimal choice of the number of compression stages, which corresponds to a compromise between increasing the electrical efficiency and decreasing the system complexity and costs (stem from the number of stages and total footprints). The configuration with three compression stages is an optimal solution in our case.

\subsection{Effect of the effectiveness of intercooling HEX}

As outlined in the introduction, the theoretical investigation of this

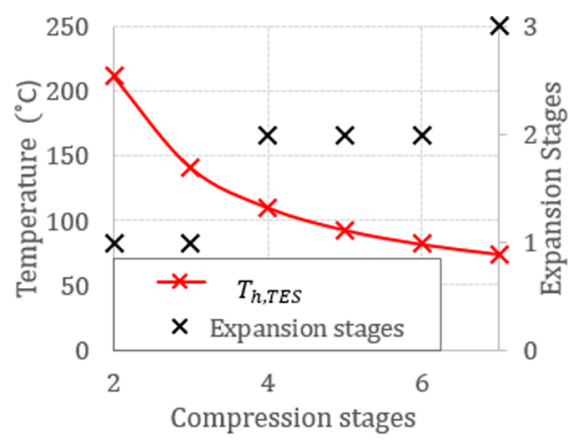

a. Temperature of hot TES (left axis) and required expansions stages (right axis) as a function of the number of compression stages.

(Solid line for first configuration and dashed line for the second)

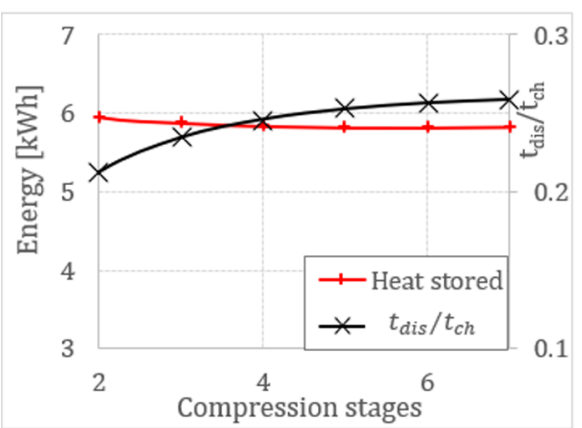

c. Heat stored (left axis) and the discharge to charge time ratio (right axis) as a function of the number of compression stages

(Solid line for first configuration and dashed line for the second)
Fig. 6. (a) Temperature of hot TES (left axis) and required expansions stages (right axis) as a function of the number of compression stages. (Solid line for first configuration and dashed line for the second). (b) TCAES efficiencies as a function of the number of compression stages. (c) Heat stored (left axis) and the discharge to charge time ratio (right axis) as a function of the number of compression stages (Solid line for first configuration and dashed line for the second). (d) The total required HEX footprints as a function of the number of compression stages. 
parameter has been the subject of the study of Han and Guo [35]. Notwithstanding, their analysis is based on variable compression and expansion ratios. Alternatively, in this study, the effect of HEX effectiveness was carried out with a constant design temperature of TES respecting the current practical applications of HEX.

On the basis of the previous results, the following parameters are fixed as follow:

1 Number of compression stages $N_{c}=3$.

2 Maximum pressure $P_{\max }=200$ bars.

3 The effectiveness of expansion HEX $\varepsilon_{e}=0.85$

4 The temperature of the hot TES is fixed to $140{ }^{\circ} \mathrm{C}$.

Since the charge parameters of the two configurations are the same, only the results of the first configuration are presented in Fig. 7(a)-(c).

Fig. 7(a) shows that the energy density grows linearly with the effectiveness which arises from the drop of the temperature of the air inlet flowing to the air reservoir. In addition, the discharge to charge time ratio surges steadily with the effectiveness at the beginning, then it remains almost constant when the effectiveness is between 0.79 and 0.85 and it drops sharply when the effectiveness is above 0.93 . The rise of this ratio mainly comes from the decrease of the charge time due to the growing of the air mass flow rate, and also to the increase of the discharge time due to the growing of the energy density. On the other hand, the decline of this ratio is due to the pressure losses that affect adversely the airflow and the charge time.

It is obvious that the improvement of the effectiveness increase proportionally the heat delivered by each HEX. By combining this with the rise of the charge time, the heat stored and the heating energy increase significantly as can be seen from Fig. 7(b). Another conclusion which can be revealed from this figure is that the cooling energy increases linearly ascribed to the rise of the discharge time.

In Fig. 7 (c), the gain in the heat energy stored yields to the increase in the heat recuperated which gives rise to the electrical efficiency. As well, this increment with the increasing of the heating and cooling energy originates in the improvement of the comprehensive efficiency. Comparing Fig. 7 (a) and (c) shows that the discharge to the charge ratio and the electrical and comprehensive efficiency share the same behavior due to the fact that the compression and expansion powers are constant. All in all, the electrical and comprehensive efficiency increase moderately about $8 \%$ and $14.5 \%$ respectively from their initial values when the effectiveness goes from 0.65 to 0.85 . It's important to note that these behaviors still in line with the results of Han and Guo [35] despite of the difference in the simulation conditions.

Finally, as can be found in Fig. 7(c), the total HEX footprints rise moderately ( $26 \%$ of its initial value) when the effectiveness goes from 0.65 to 0.83 and then significantly ( $41 \%$ of its initial value) when the effectiveness is above 0.85 .

These analyses below allows us to conclude that the effectiveness of intercooling HEX should be chosen as an optimal trade-off between the system performances (efficiencies, cooling and heating energy) and the required footprints. In our cases, the optimal effectiveness is a value in the range of 0.77 to 0.86 .

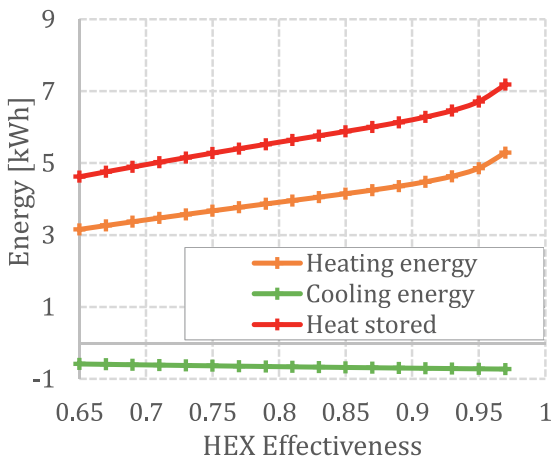
function of the effectiveness of intercooling HEX b. Heating, cooling and stored energy as a

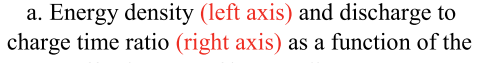
effectiveness of intercooling HEX. .
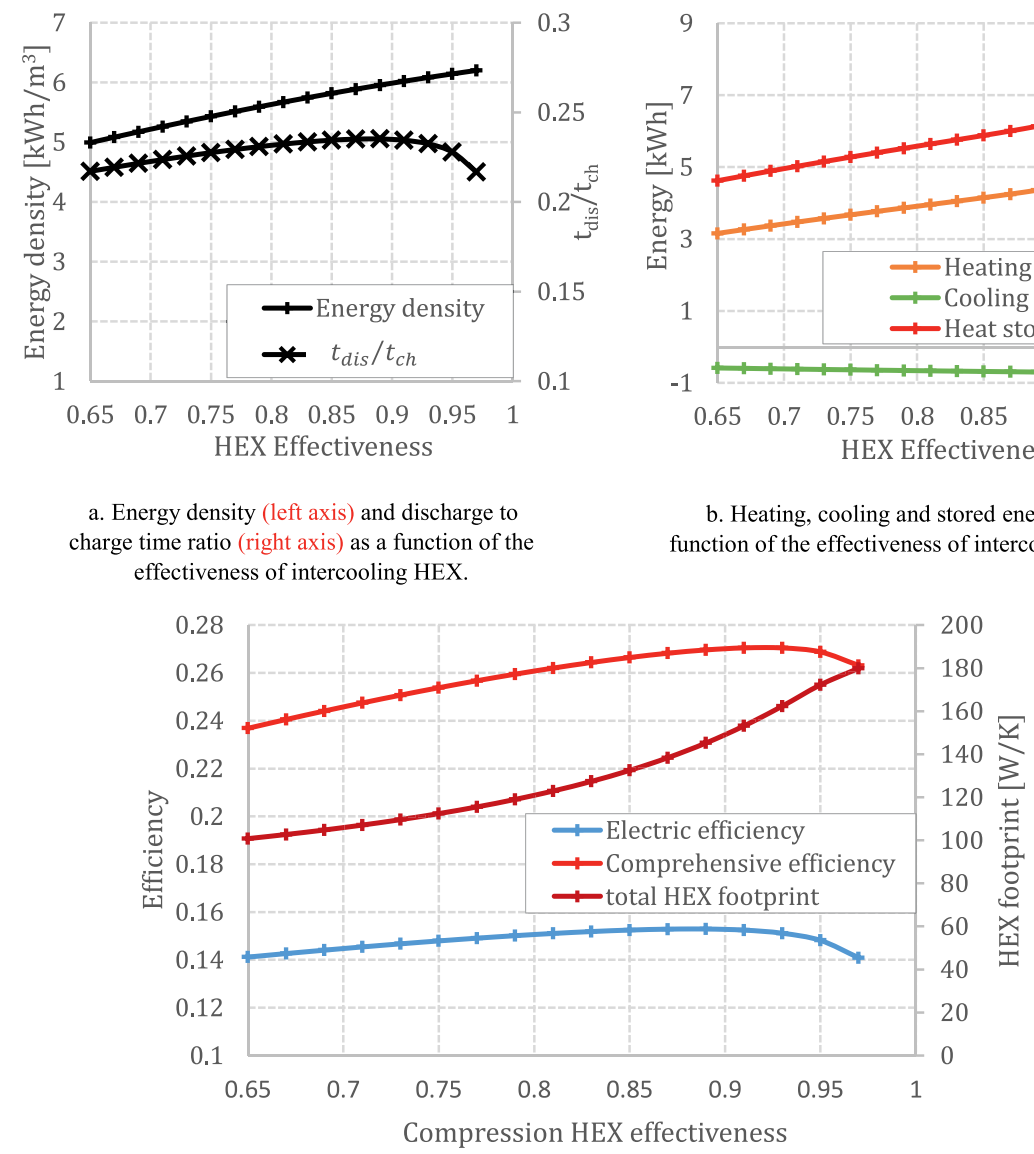

c. T-CAES efficiencies (left axis) and the total HEX footprints (right axis) as a function of the effectiveness of intercooling HEX.

Fig. 7. (a) Energy density (left axis) and discharge to charge time ratio (right axis) as a function of the effectiveness of intercooling HEX. (b) Heating, cooling and stored energy as a function of the effectiveness of intercooling HEX. (c)T-CAES efficiencies (left axis) and the total HEX footprints (right axis) as a function of the effectiveness of intercooling HEX. 


\subsection{Effect of the effectiveness of discharge phase HEX}

Here, the same fixed parameters of the previous Section 3.3 were adopted with the exception of taking $\varepsilon_{c}=0.85$ and $\varepsilon_{e}$ varying in the range of 0.65 to 0.97 .

Fig. 8(a) and (b) report the simulation results in terms of the heating and cooling energy and performances respectively. The first important point to underline is that there is a critical value of the effectiveness at 0.79 on which the number of turbines can be reduced from two to one. In the two range of variation of effectiveness $([0.65 ; 0.77]$ and $[0.79 ; 0.97])$ the parameters variations are similar.

In the first configuration, it can be noticed that there is a linear rise of $27.6 \mathrm{~W} / 0.01$ for the heating energy upon a decline of about $1{ }^{\circ} \mathrm{C} /$ 0.01 of the temperature of the cold TES, which results in a total drop from $66.5{ }^{\circ} \mathrm{C}$ to $33.13{ }^{\circ} \mathrm{C}$. This is originated from the proportional relation between $\varepsilon_{e}$ and Pinch $_{e}$ on the hand, and the heating energy on the other hand. Physically speaking, at low levels of HEX effectiveness the drop of the heating energy is elicited by the heat wasted from the cold TES reservoir to the environment. As for cooling energy, it is predicted that it remains constant as the temperature input of AM is unchanged. Owning that the temperature input and output of each turbine are also unchanged, the electrical efficiency remains constant at $14.5 \%$ then $15.2 \%$ (Fig. 8 (b)). On the other hand, the comprehensive efficiency increases a few as $2.5 \%$, which is accounted for the heating energy.

In the second configuration, in Fig. 8(a), the cold TES temperature declines as long as the effectiveness rises. The heating energy and also the cooling energy barely increase when $\varepsilon_{e}$ is below 0.77 and adversely when $\varepsilon_{e}$ is above 0.77 . Those effects are related in the first place to the rise of the preheating energy delivered to the air side and the increase of the amount of heat of the recooling HEX before the AM in the second place. For these reasons also, according to Fig. 8(b), the electrical efficiency and the comprehensive efficiency slowly go up with a slope of $0.5 \% / 0.15$ and $0.3 \% / 0.15$ respectively.

Finally, the total footprints of HEX in the two configurations slowly rises as the effectiveness is below 0.83 , by contrast it increases dramatically as the effectiveness is above 0.85 .

To conclude, it is crucial to choose the effectiveness of HEX above a critical value (at 0.79 in our case) in order to reduce the number of expansion stages. The overall efficiencies can be kept as high as expected even if the effectiveness is at moderate values ( $[0.79 ; 0.85]$ in our case). Furthermore, in the first configuration, an additional option to economize in terms of the area of HEX area is to impose the effectiveness as lower as possible conditionally upon using the water mass of cold TES reservoir for heating purposes.

\subsection{Effect of the maximum storage pressure}

In order to isolate the effect of the number of compression stages they are fixed to two and the other parameters are chosen as follow:

1 The minimum pressure is $P_{\min }=25$ bars.

2 The effectiveness of HEX $\varepsilon_{e}=\varepsilon_{c}=0.85$

$3 T_{h}$, TES is the maximum possible value $\left(C_{\min }=C_{\max }\right.$ for intercooling HEX).

Based on the perfect gas relation, the stored air mass and the time of charge are proportional to the maximum storage pressure so that the energy density rises linearly as evident in Fig. 9(a). On the other side, the required charge time is greater than of the discharge one because of the former is proportional to $\beta^{5}$ (see Eq. (A3.3)), evidence for this is in Fig. 9(a) where the discharge to charge ratio declines mostly from 30 bars to 180 bars.

The inspection of Fig. 9(b) indicates that the heat stored and the heating energy increase significantly with the maximum storage pressure, which is originated from two major effects: the increase of the discharge time and the rise of the heat power (due to the increase of the temperature output of each compression stage). Besides, the heat recuperated in the discharge phase increases, it can be seen by regarding the difference between points of the graph of the heat stored and of the heating energy in Fig. 9(b). Simultaneously, for the past reasons, in Fig. 9(c), the electric and the comprehensive efficiencies plunge down over than $36 \%$ and $23 \%$ respectively from their initial values at $23.2 \%$ and $33.5 \%$ as the pressure goes from 30 bars to 130 bars. Afterwards the two electric and comprehensive efficiencies decrease moderately with a proportion of $12 \%$ and $8 \%$ respectively.

Regarding to the required HEX footprints shown in Fig. 9(c), the total footprint decreases as high as $50 \%$ when the pressure rises to 130 bars and then as lower as $11 \%$.

To sum up, increasing the ratio of maximum to minimum reservoir pressure $\delta$ below than 5.2 (which correspond to $P_{\max }<$ 130 when $P_{\min }=25$ ) entails substantial decrease on the system performance and the required footprints, while the energy density increases linearly. It is difficult to find a trade-off between the performances and the energy density so that the choice of the maximum pressure will be governed by the system application and cost.

However, Proczka et al. [53] showed that the cost consequences of operating a pressure vessel at too low pressure are more severe than at too high. As a result, keeping a low value of the ratio $\delta$ of the maximum to minimum pressures, let us say 2.5 , and increasing the maximum pressure, as the simulation results illustrated in Fig. 10, the efficiency drop is prevented while having the opportunity to achieve a high energy

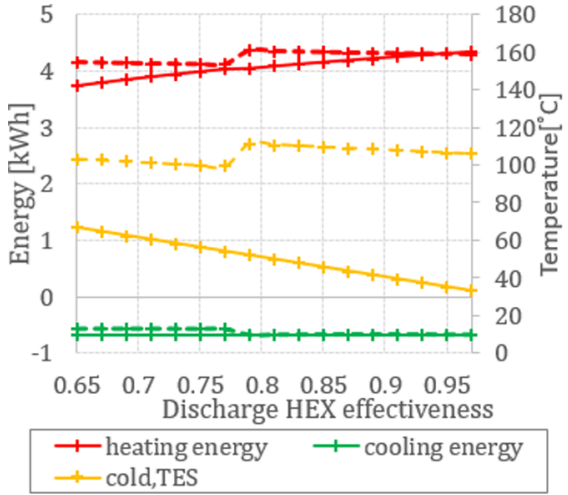

a. Temperature of cold TES (right axis), heating and cooling energy (left axis) as a function of the effectiveness of discharge phase HEX.

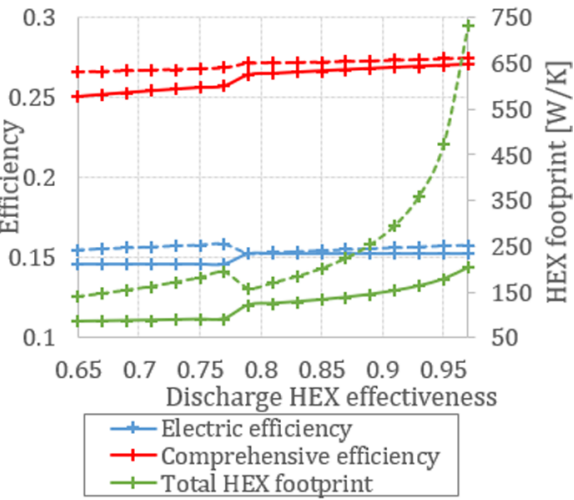

b. T-CAES efficiencies (left axis) and the total HEX

footprints (right axis) as a function of the effectiveness of discharge phase HEX.
Fig. 8. (a) Temperature of cold TES (right axis), heating and cooling energy (left axis) as a function of the effectiveness of discharge phase HEX. (Solid line for first configuration and dashed line for the second). (b) T-CAES efficiencies (left axis) and the total HEX footprints (right axis) as a function of the effectiveness of discharge phase HEX. 


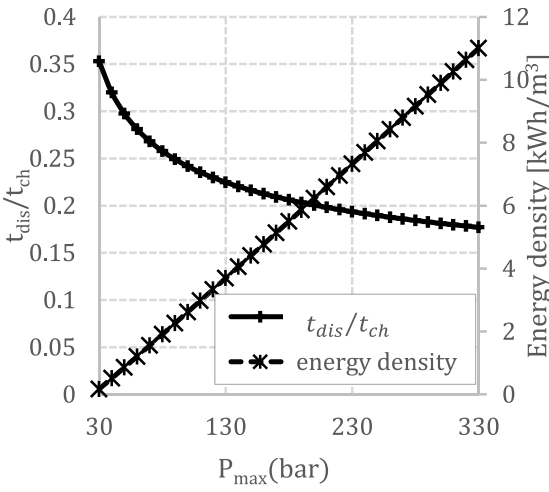

a. Discharge to charge time ratio (left axis) and energy density (right axis) as a function of the maximum storage pressure. (Solid line for first configuration and dashed line for the second) b. High temperature of TES (right axis) and
heating, cooling and stored energy (left axis) as a function of the maximum storage pressure.

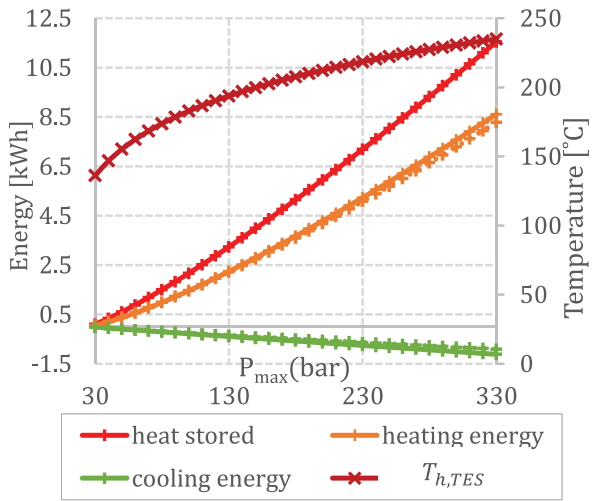

\section{.}

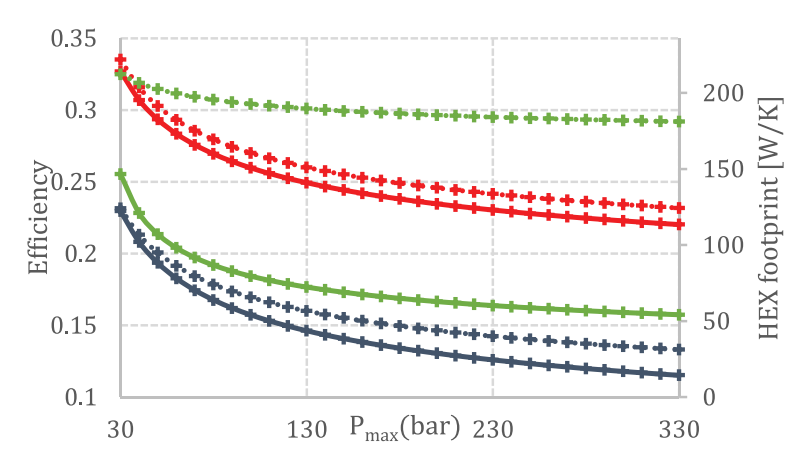

—electric efficiency $\quad$ - comprehensive efficiency
-Total HEX footprints

c. T-CAES efficiencies (left axis) and the total HEX footprints (right axis) as a function of the maximum storage pressure. (Solid lines for the first configuration and dashed lines for the second one)

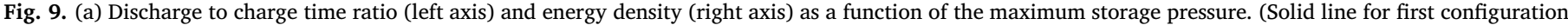

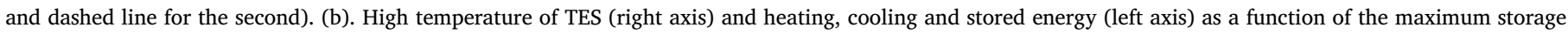

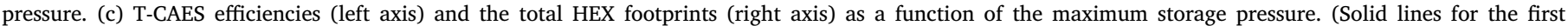
configuration and dashed lines for the second one).

density as long as the maximum pressure increases. It is important to stress that this optimization opportunity entails the study of the possibility to construct a turbine or an AM, which operates at high pressures.

Finally, it is convenient to compare our results with the literature despite of the difference in the system configuration. The maximum pressure effect is in line with of Liu and Wang [8] and Facci et al. [6] but it was found by these last authors that the ratio $\delta$ has a minor effect which caused by an assumption of variable pressure ratio of machinery.

\subsection{Effect of the cooling energy}

Based on the simulations results in the above sections, an optimal selection (stressing that an optimal and not the optimal) of the above parameters is listed in Table 2 where the maximum storage pressure is chosen by giving preference to the energy density.

Table 3 summarizes the effect of disabling the cooling energy on system energy output, performances and HEX footprints. Similarly, the efficiencies of the second configuration are very slowly higher than of the first configuration in all cases. Comparing the first two lines for each configuration, when the system operates without cooling the electrical efficiency is improved by $1.5 \%$ but the comprehensive efficiency is dropped by $4 \%$, which underlines that the heating and cooling energy have greater effect on the comprehensive efficiency. Another important conclusion which can be deduced is that when the system is intended for a site without cooling demand the second configuration is more advantageous economically since the total HEX footprint is $22 \%$ lower than the first configuration, and when the cooling is needed in the system the opposite is true.

\subsection{Characteristic of the micro-scale T-CAES}

It is of great practical importance to derive all the parameters of the subsystems so that the output parameters of each compound are illustrated in the three tables of Appendix 2 for the first configuration

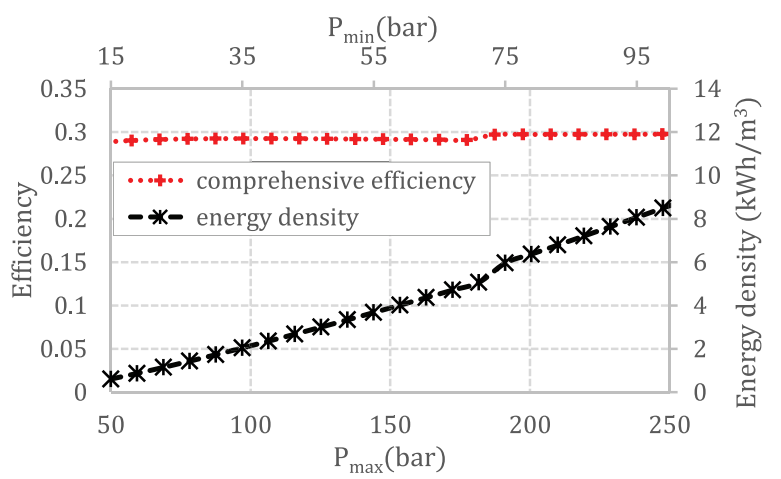

Fig. 10. Comprehensive efficiency (left axis) and energy density (right axis) at constant maximum to minimum pressure ratio as a function of the maximum storage pressure (the variation of the minimum storage pressure is shown in the secondary $x$-axis on the top). 
Table 2

Optimal solution of the design parameters.

\begin{tabular}{ll}
\hline Parameters & Value \\
\hline Temperature of h,TES $\left[{ }^{\circ} \mathrm{C}\right]$ & 140 \\
Effectiveness of compression HEX & 0.85 \\
Effectiveness of expansion HEX & 0.82 \\
Maximum pressure of compressed air [bar] & 200 \\
Number of compression stages /expansion stages & $3 /$ one turbine stage and an \\
& AM \\
\hline
\end{tabular}

enabling the cooling production. The parameters given in Table 2 are adopted.

As illustrated previously in Table 3, the electric round trip efficiency is low at $15.25 \%$. Evidences for that can be found in Table A2.1 and the main causes are as follows:

1 The electric energy input was $11.09 \mathrm{kWh}$ but the heat stored was $52 \%$ lower at $5.9 \mathrm{kWh}$. This is not only related to the effectiveness of HEX but mainly to the unavoidable heat lost by the volumetric compressors (expressed by its polytropic coefficient).

2 Since the compression to expansion pressure ratio is high, the ratio of the heat recuperated at $1.22 \mathrm{kWh}$ to the heat stored at $5.9 \mathrm{kWh}$ is at about $21 \%$. In other words, important losses are located on the expansion valve restricting the use of available heat. Justification of that can be found in [37].

3 Referring back to the thermodynamic to the existing mechanical conversion of turbine and air motor, which are 0.62 and 0.30 respectively. Thus, it is predictable to have a low round trip efficiency, which is on good agreement with the founding of the studies previously mentioned in the introduction: the electric efficiency is mainly affected by the efficiency of turbines and compressors.

In addition, in spite of the electric power output of expanders $(2.06 \mathrm{~kW})$ is $65 \%$ lower than of the compressors $(3.17 \mathrm{~kW})$, the discharge time (51 $\mathrm{min}$ ) was $24 \%$ lower than of the charge phase which is related to the poor electric efficiency.

In Table A2.2, as predicted in the model, the pressure losses in the two first intercooling heat exchangers can be neglected compared to the last HEX. Consequently, the pressure losses in the discharge phase HEX can be ignored when the minimum to maximum pressure ratio $\delta$ is high. An important feature which can be noticed which is the heat exchanger footprint of the first HEX is higher than the last one due to the fact that in spite of the same value of effectiveness, the LMTD changes according the temperature levels. Hence, the effectiveness of the last HEX can be much higher in order to increase the energy density and the round trip efficiency of the system (see Section 3.3).

In Table A2.3, in spite of the expansion ratio of the turbine is lower than the AM, the power delivered by the turbine is higher than of the AM, which is linked to the low expansion temperature of the AM and its lower efficiency of conversion. Since the mass flow rate of the discharge phase is higher than of the charge phase, the heat duty of the discharge HEX is greater. Thus, the footprints of this later are the most important (about three times of the charge HEX).

\section{Conclusions and perspectives}

This paper proposes a configuration of trigenerative compressed air energy storage giving priority to electrical energy production. Then, a complete thermodynamic model of the whole system was developed. The design parameters of each compound are settled as input parameters, while the output parameters consist of a set of evaluation criteria (such as system performances and energy density), parameters reflecting the cost (heat exchanger footprints and the number of compression and expansion stages) as well as other useful parameters which are important for prospective engineering applications (such as the charge or discharge times, pressures and temperatures at the inlet/outlet of each component). The main uncertainties of the model rely on considering constant polytropic coefficient of the air motor independently from the inlet temperature and ignoring the cooling energy between the throttling valve output and the first heat exchanger of the discharge phase.

According to the design methodology of heat exchangers and the need, whether to maximize the round-trip electric efficiency or reduce the total heat exchanger area, two configurations are deduced and discussed. The first configuration is intended to simplify the design by reducing the number of heat exchangers and by reusing the water of the discharge process in the charge process, while the aim of the second configuration is to optimize the electric efficiency by maximizing the preheating energy before the expanders.

After being demonstrated that there is an optimal number of expansion stages, which can be found by a numerical iteration procedure. An optimization via a parametric study is conducted for the two configurations in order to provide a guideline for an optimal selection of the design parameters. The main contribution of the paper is that the optimization is based on the investigation of the mutual effect of the parameters and their impact on the criteria listed above. The following conclusions could be drawn:

1 The temperature level of the hot thermal energy storage has a marginal effect on the system efficiencies (not more than 1.5\%). However, the accurate temperature level should be high to ensure a minimal number of expansion stages and to lower the total heat exchanger footprints at constant number of stages $\left(120^{\circ} \mathrm{C}\right.$ or $150{ }^{\circ} \mathrm{C}$ and $90^{\circ} \mathrm{C}$ or $130{ }^{\circ} \mathrm{C}$ were the optimal values for the first and second configurations respectively).

2 The optimal choice of the number of compression stages and the effectiveness of heat exchangers is based on a compromise between the system efficiencies (comprehensive efficiency and electrical efficiency) on one side, and the number of expansion stages and the heat exchangers footprints on the other side. Three compression stages were sufficient when the maximum pressure reaches 200 bars.

3 The choice of the maximum storage pressure has a significant effect on the system efficiencies (with a deviation of up to $12 \%$ ) and the energy density. There is no trade-off between these criteria and the optimal choice will be based upon the cost and the benefits of the system.

4 There is no need to design the heat exchanger with very high effectiveness since it leads to an adverse effect on the whole system efficiency (because of pressure losses) and rises the required footprints. The optimal range of effectiveness is found between 0.79 and 0.85 .

Table 3

Energy outputs, efficiencies and total HEX footprints of the two configuration with and without enabling the cooling energy.

\begin{tabular}{|c|c|c|c|c|c|}
\hline & Cooling energy (kWh) & Electrical efficiency (\%) & Comprehensive efficiency (\%) & Total HEX footprint (W/K) & Heating energy (kWh) \\
\hline \multirow[t]{2}{*}{ First configuration } & 0 & 16.66 & 22.53 & 193.8 & 2.61 \\
\hline & 0.68 & 15.25 & 26.53 & 125.1 & 4.10 \\
\hline \multirow[t]{2}{*}{ Second configuration } & 0 & 16.90 & 23.75 & 149.2 & 3.04 \\
\hline & 0.67 & 15.40 & 27.19 & 177.4 & 4.34 \\
\hline
\end{tabular}


5 Enabling the cooling energy at the last expansion stage has a greater effect on the comprehensive efficiency (rises by 4\%) than the electrical efficiency (drops by $1.5 \%$ ) which provides support to the benefits of the system configurations without preheating in the discharge phase proposed previously in the literature.

6 The two configurations studied present low differences in terms of global efficiencies. On the other hand, it is economically more viable in terms of heat exchangers footprints to adopt the first configuration when the system is intended to produce cooling energy and the second configuration otherwise.

At micro scale applications, based on existing technologies and applying an optimal choice of the design parameters, the electrical efficiency is low at $17 \%$. On the other hand, the cooling and heating energy improves the system efficiency by almost $11.5 \%$. The main causes of the low values of efficiencies and the possible solutions are illustrated as follow:

1. In order to keep a high energy density the maximum storage pressure should be high so that the losses in the throttling valve are significant. This can be avoided by:

- Keeping a low ratio of the maximum to minimum pressure while increasing the values of this later. This raises the question to develop a new expansion micro-scale machinery which operates at high pressure.

- Applying a machinery with variable expansion pressure ratio as proposed by Han and Guo [35]. However, the study of the technical feasibility in terms of technology and coupling the thermal energy storage compound of such solutions are needed.

2. At a micro-scale, the efficiency of turbines and notably the air motor are very low. Increasing the scale of the system and replacing the air motor with a scroll expander (despite its low expansion ratio) makes the application more interesting in terms of the global efficiencies.

Finally, it can be deduced that the parametric optimization procedure developed based on the mutual effect of parameters is able to provide optimal solutions for the design of trigenerative compressed air energy storage systems. The importance of this optimization procedure lies in its ability to be extended to optimize the adiabatic compressed air energy storage since this later forms a part of the configuration introduced here. Future work will focus on the integration of an economic model with the aim of finding the accurate optimal techno economic solutions.

Generally, future investigations should focus on the optimization of the performances of the system via the following research opportunities:

1. Technology development of expander machineries to work under variable pressure with high input pressure. The air piston expanders would be a good candidate since the existing expanders operates with a variable pressure and could be designed with high pressure input analogous to the compressors.

2. Investigation on the feasibility study of coupling the heat exchangers and thermal energy storage with the air side operating at variable pressures, temperatures and mass flowrates as a complementary study to $[6,35]$.

\section{Acknowledgments}

M.C. and S.P. acknowledge the financial support of the Natural Sciences and Engineering Research Council of Canada (NSERC) and the company Sigma Energy Storage Inc. through a Collaborative Research and Development grant (386141936).

\section{Appendix 1}

General definition of HEX efficiency is:

$\varepsilon=\frac{C\left(T_{\text {in }}-T_{\text {out }}\right)}{C_{\min }\left(T_{\text {in,hot }}-T_{\text {in, cold }}\right)}$

In the charge phase, in order to maximize the cooling efficiency of the compressed air and consequently the global electric efficiency, the minimal thermal capacity is to be attributed to the air side.

As a result $C_{\min }=\dot{m}_{a, c} . C_{p, a}$ and $C_{\max }=\dot{m}_{w, c h, i} . C_{p, w}$

Hence, the effectiveness is expressed by:

$\varepsilon_{c h}=\frac{T_{i n, c, i}-T_{i n, c, i+1}}{T_{i n, c, i}-T_{\text {cold }, T E S}}$

In the discharge phase, Fig. A1.1 shows the difference between the two designs concepts by means of temperature variation for an imposed heat duty.

As mentioned in Section 2, in the first configuration the output temperature of water flow should be the minimal possible value. Consequently, $C_{\min }$ belongs to the water side and $C_{\max }$ to the air side.

As a result $C_{\max }=\dot{m}_{a, e} . C_{p, a}$ and $C_{\min }=\dot{m}_{w, d i s, j} . C_{p, w}$

The effectiveness gets:
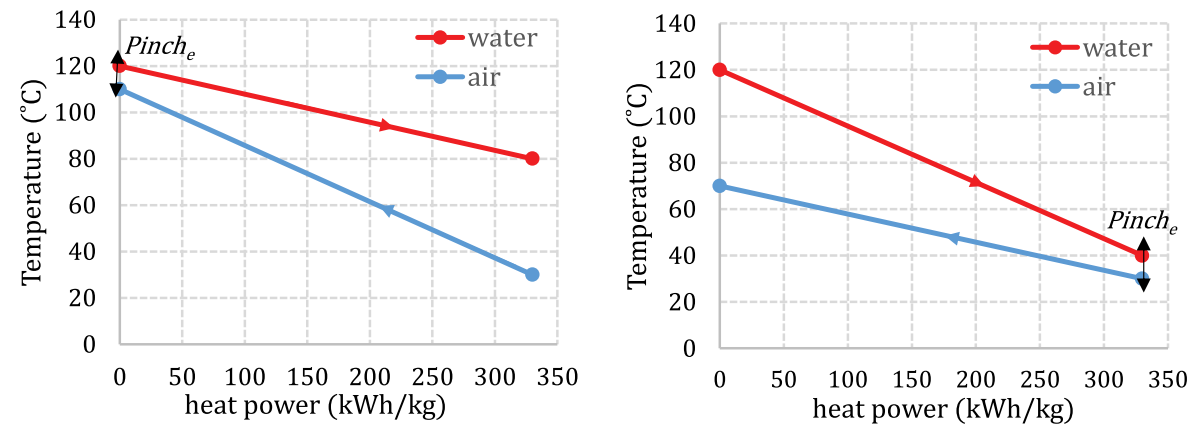

Fig. A1.1. variation of temperature of air and water flow versus heat duty for the first configuration (right) and second configuration (left). 
$\varepsilon_{e, 1}=\frac{T_{h, T E S}-T_{\text {out }, \text { dis }, j}}{T_{h, T E S}-T_{\text {out }, e, j-1}}=\frac{C_{\max }\left(T_{\text {out }, e, j-1}-T_{\text {in }, e, j}\right)}{C_{\min }\left(T_{h, T E S}-T_{\text {out }, e, j-1}\right)}$

In the second configuration, the input temperature of the air flow at the air turbine should be chosen the maximum possible, thus $C_{\min }$ belongs to the air side and the effectiveness become:

$\varepsilon_{e, 2}=\frac{T_{\text {in }, e, j}-T_{\text {out }, e, j-1}}{T_{h, T E S}-T_{\text {out }, e, j-1}}=\frac{C_{\text {max }}\left(T_{h, t e s}-T_{\text {out }, \text { dis }, j}\right)}{C_{\min }\left(T_{h, T E S}-T_{\text {out }, e, j-1}\right)}$

where $C_{\min }=\dot{m}_{a, e} . C_{p, a}$ and $C_{\max }=\dot{m}_{w, d i s, j} . C_{p, w}$

For the first configuration the pinch occurs at the output of water flow, whereas for the second configuration the pinch takes place at the input of water flow, so that:

for the $1^{\text {st }}$ config: Pinch $_{e}=T_{\text {out }, \text { dis }, j}-T_{\text {out }, e, j-1}$

for the $2^{\text {nd }}$ config: Pinch $_{e}=T_{h, T E S}-T_{\text {in,e,j }}$

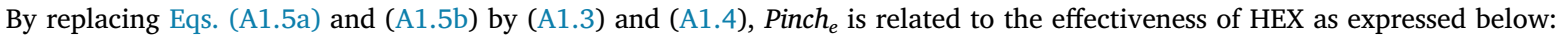

Pinch $_{e}=\left(1-\varepsilon_{e}\right)\left(T_{h, T E S}-T_{\text {out }, e, j-1}\right)$

It should be noted that this relation is very useful to derive the temperatures at the input/output of HEX.

\section{Appendix 2}

This appendix presents the useful output parameters of the model for prospective engineering applications of the trigenerative compressed air energy storage.

Table A2.1

Output parameters of the charge phase for the first configuration.

\begin{tabular}{|c|c|c|c|c|c|c|c|}
\hline Compressors & $\begin{array}{l}\text { Stage } 1 \\
\text { in }\end{array}$ & $\begin{array}{l}\text { out } \\
\text { HEX } 1\end{array}$ & $\begin{array}{l}\text { Stage } 2 \\
\text { in }\end{array}$ & $\begin{array}{l}\text { out } \\
\text { HEX } 2\end{array}$ & $\begin{array}{l}\text { Stage } 3 \\
\text { in }\end{array}$ & $\begin{array}{l}\text { out } \\
\text { HEX } 3\end{array}$ & $\begin{array}{l}\text { Air tank } \\
\text { in }\end{array}$ \\
\hline HEX & & in & out & in & out & in & out \\
\hline Pressure drop [bar] & & 0.28 & & 1.62 & & 9.41 & \\
\hline Density $\left[\mathrm{kg} / \mathrm{m}^{3}\right]$ & 1.17 & 4.95 & 6.37 & 27.04 & 36.59 & 155.41 & 212.47 \\
\hline $\begin{array}{l}\text { Air temperature } \\
{\left[{ }^{\circ} \mathrm{C}\right]}\end{array}$ & 30.00 & 161.97 & 49.79 & 190.38 & 54.06 & 196.50 & 54.98 \\
\hline $\begin{array}{l}\text { HEX footprint [W/ } \\
\mathrm{K}]\end{array}$ & & 23.16 & & 16.49 & & 15.79 & \\
\hline Heat Power [kW] & & 0.483 & & 0.587 & & 0.610 & \\
\hline
\end{tabular}

Table A2.2

Output parameters of the discharge phase for the first configuration.

\begin{tabular}{|c|c|c|c|c|c|}
\hline HEX & $\begin{array}{l}\text { HEX-1 } \\
\text { in }\end{array}$ & $\begin{array}{l}\text { out } \\
\text { Turbine }\end{array}$ & $\begin{array}{l}\text { HEX-2 } \\
\text { in }\end{array}$ & $\begin{array}{l}\text { out } \\
\text { AM }\end{array}$ & \\
\hline Expanders & & in & out & in & out \\
\hline Power [kW] & & 1.347 & & 0.715 & \\
\hline Pressure [bar] & & 25.00 & 6.00 & 6.0 & 1.01 \\
\hline Air temperature $\left[{ }^{\circ} \mathrm{C}\right]$ & 30.00 & 111.0 & 30.0 & 30.0 & -15.2 \\
\hline Water temperature $\left[{ }^{\circ} \mathrm{C}\right]$ & 48.8 & & 0 & & \\
\hline Heat recuperated [kW] & 1.488 & & 0 & & \\
\hline Water mass flow $[\mathrm{kg} / \mathrm{s}]$ & 0.004 & & 0 & & \\
\hline HEX footprint $[\mathrm{W} / \mathrm{K}]$ & 70.66 & & 0 & & \\
\hline
\end{tabular}

Table A2.3

Main output parameters of the model for the first configuration.

\begin{tabular}{ll}
\hline Charge phase & \\
\hline Charge time $[\mathrm{h}]$ & 3.5 \\
Air mass flow $[\mathrm{kg} / \mathrm{s}]$ & 0.0043 \\
Air stored $[\mathrm{kg}]$ & 54.1 \\
Water stored $[\mathrm{kg}]$ & 46
\end{tabular}


Table A2.3 (continued)

\begin{tabular}{ll}
\hline End of Storage phase & \\
\hline Temperature of TES $\left[{ }^{\circ} \mathrm{C}\right]$ & 134.5 \\
Air temperature $\left[{ }^{\circ} \mathrm{C}\right]$ & 30 \\
Air pressure [bar] & 186.7 \\
\hline Discharge phase & \\
\hline Discharge time [h] & 0.82 \\
Water remained on h,TES tank [kg] & 12.26 \\
Water pumped to cold,TES tank $[\mathrm{kg}]$ & 33.73 \\
\hline Energy balance & \\
\hline Electric energy input $[\mathrm{kWh}]$ & 11.1 \\
Heat stored $[\mathrm{kWh}]$ & 5.88 \\
Heat loss $[\mathrm{kWh}]$ & 0.562 \\
Recuperated heat $[\mathrm{kWh}]$ & 1.22 \\
Heating energy [kWh] & 4.1 \\
Cooling energy [kWh] & 0.68 \\
Electric energy output $[\mathrm{kWh}]$ & 1.7 \\
\hline
\end{tabular}

\section{Appendix 3}

This appendix presents the useful equations deduced from the model of Cheayb et al. [37] which are used in this study.

\section{A3.1. Modeling of compressor chain}

Output and input temperatures of each stage and compression mass flow rate are calculated by Eqs. (A3.1)-(A3.3) as demonstrated in ref [37].

$T_{\text {out }, c, i}=T_{i n, c, i} \cdot \beta_{c, i} \frac{n_{c, i-1}}{n_{c, i}}$

$T_{i n, c, i+1}=T_{a m b}+$ Pinch $_{c, i}$

where Pinch $_{c, i}=\left(1-\varepsilon_{c, i}\right)\left(T_{\text {out }, c, i}-T_{a m b}\right)$

$\dot{m}_{c}=\frac{\eta_{e} \cdot \eta_{m} \dot{W}_{e l}}{C_{p, a} \cdot \sum_{i=1}^{N c} \frac{\gamma-1}{\gamma} \frac{n_{c, i}}{n_{c, i}-1}\left(\left(T_{a m b}+\operatorname{Pinch}_{c, i-1}\right) \cdot\left(\beta_{c, i} \frac{n_{c, i}-1}{n c_{i}}-1\right)\right)}$

\section{A3.2. Modeling of air reservoirs}

The same equations developed in [37] are used to find the mass stored (A3.4) and the time of charge (A3.5):

$m_{s}=N_{\text {res }} \frac{\left(P_{\max }-P_{\min }\right) \cdot V_{\text {res }}}{r . T_{\text {in,res }}}$

$t_{c h}=\frac{m_{s}}{\dot{m}_{c}}$

During the storage phase, the temperature and pressure are accounted by Eqs. (A3.6) and (A3.7).

$T(t)=T_{a m b}+\left(T_{(t=0)}-T_{a m b}\right) e^{\frac{-N_{\text {res. }}}{m_{\text {air }} \cdot C_{p a} \cdot R_{t h}}}$

$P_{\text {res }}(t)=\frac{m_{\text {air. }} \cdot r \cdot T_{\text {res }}(t)}{N_{\text {res }} \cdot V_{\text {res }}}$

where $m_{\text {air }}$ denotes the total mass of air stored in the tanks:

$m_{\text {air }}=N_{\text {res }} \frac{P_{\text {max }} V_{\text {res }}}{r . T_{\text {in,res }}}$

where $R_{t h}$ is the average thermal resistance of the natural boundary layer (see for further details on ref [37]).

Finally, in the discharge phase, once expansion air flow is imposed, the discharge is calculated by (A3.9).

$t_{d i s}=\frac{m_{s}}{\dot{m}_{e}}$ 


\section{References}

[1] X. Luo, J. Wang, M. Dooner, J. Clarke, Overview of current development in elec trical energy storage technologies and the application potential in power system operation, Appl. Energy 137 (2015) 511-536.

[2] H. Chen, T.N. Cong, W. Yang, C. Tan, Y. Li, Y. Ding, Progress in electrical energy storage system: a critical review, Prog. Nat. Sci. 19 (3) (2009) 291-312.

[3] G.C. Gissey, P.E. Dodds, J. Radcliffe, Market and regulatory barriers to electrical energy storage innovation, Renew. Sustain. Energy Rev. 82 (2018) 781-790.

[4] M. Peker, A.S. Kocaman, B.Y. Kara, Benefits of transmission switching and energy storage in power systems with high renewable energy penetration, Appl. Energy 228 (2018) 1182-1197.

[5] F. Klumpp, Comparison of pumped hydro, hydrogen storage and compressed air energy storage for integrating high shares of renewable energies-Potential, costcomparison and ranking, J. Energy Storage 8 (2016) 119-128.

[6] A.L. Facci, D. Sánchez, E. Jannelli, S. Ubertini, Trigenerative micro compressed air energy storage: Concept and thermodynamic assessment, Appl. Energy 158 (2015) 243-254.

[7] S. Lv, W. He, A. Zhang, G. Li, B. Luo, X. Liu, Modelling and analysis of a novel compressed air energy storage system for trigeneration based on electrical energy peak load shifting, Energy Convers. Manage. 135 (2017) 394-401.

[8] J.L. Liu, J.H. Wang, Thermodynamic analysis of a novel tri-generation system based on compressed air energy storage and pneumatic motor, Energy 91 (2015) 420-429.

[9] E. Jannelli, M. Minutillo, A.L. Lavadera, G. Falcucci, A small-scale CAES (compressed air energy storage) system for stand-alone renewable energy power plant or a radio base station: a sizing-design methodology, Energy 78 (2014) 313-322.

[10] Y. Li, X. Wang, D. Li, Y. Ding, A trigeneration system based on compressed air and thermal energy storage, Appl. Energy 99 (2012) 316-323.

[11] D. Zafirakis, J.K. Kaldellis, Autonomous dual-mode CAES systems for maximum wind energy contribution in remote island networks, Energy Convers. Manage. 51 (11) (2010) 2150-2161.

[12] M. Budt, D. Wolf, R. Span, J. Yan, A review on compressed air energy storage: Basic principles, past milestones and recent developments, Appl. Energy 170 (2016) $250-268$.

[13] X. Luo, J. Wang, M. Dooner, J. Clarke, C. Krupke, Overview of current development in compressed air energy storage technology, Energy Procedia 62 (2014) 603-611.

[14] A. Rogers, A. Henderson, X. Wang, M. Negnevitsky, Compressed air energy storage: thermodynamic and economic review, 2014 IEEE PES General Meeting, Conference \& Exposition, National Harbor, MD, 2014.

[15] A. Abdon, X. Zhang, D. Parra, M.K. Patel, C. Bauer, J. Worlitschek, Techno-economic and environmental assessment of stationary electricity storage technologies for different time scales, Energy 139 (2017) 1173-1187.

[16] S. Wang, X. Zhang, L. Yang, Y. Zhou, J. Wang, Experimental study of compressed air energy storage system with thermal energy storage, Energy 103 (2016) 182-191.

[17] L. Geissbühler, V. Becattini, G. Zanganeh, S. Zavattoni, M. Barbato, A. Haselbacher, A. Steinfeld, Pilot-scale demonstration of advanced adiabatic compressed air energy storage, Part 1: Plant description and tests with sensible thermal-energy storage, J. Energy Storage 17 (2018) 129-139.

[18] V. Becattini, L. Geissbühler, G. Zanganeh, A. Haselbacher, A. Steinfeld, Pilot-scale demonstration of advanced adiabatic compressed air energy storage, Part 2: Tests with combined sensible/latent thermal-energy storage, J. Energy Storage 17 (2018) $140-152$.

[19] D. Wolf, M. Budt, LTA-CAES - a low-temperature approach to adiabatic compressed air energy storage, Appl. Energy 125 (2014) 158-164.

[20] Y. Zhang, K. Yang, X. Li, J. Xu, The thermodynamic effect of thermal energy storage on compressed air energy storage system, Renew. Energy 50 (2013) 227-235.

[21] S. Zhou, J. Zhang, W. Song, Z. Feng, Comparison analysis of different compressed air energy storage systems, Energy Procedia 152 (2018) 162-167.

[22] N. Hartmann, O. Vöhringer, C. Kruck, L. Eltrop, Simulation and analysis of different adiabatic compressed air energy storage plant configurations, Appl. Energy 93 (2012) 541-548.

[23] G. Grazzini, A. Milazzo, A thermodynamic analysis of multistage adiabatic CAES, Proc. IEEE 100 (2) (2012) 461-472.

[24] G. Grazzini, A. Milazzo, Thermodynamic analysis of CAES/TES systems for renewable energy plants, Renew. Energy 33 (9) (2008) 1998-2006.

[25] H. Mozayeni, M. Negnevitsky, X. Wang, F. Cao, X. Peng, Performance study of an advanced adiabatic compressed air energy storage system, Energy Procedia 110 (2017) 71-76.

[26] X. Luo, J. Wang, C. Krupke, Y. Wang, Y. Sheng, J. Li, Y. Xu, D. Wang, S. Miao, H. Chen, Modelling study, efficiency analysis and optimisation of large-scale adiabatic compressed air energy storage systems with low-temperature thermal storage, Appl. Energy 162 (2016) 589-600.

[27] Y. He, H. Chen, Y. Xu, J. Deng, Compression performance optimization considering variable charge pressure in an adiabatic compressed air energy storage system, Energy 165 (2018) 349-359.

[28] L. Szablowski, P. Krawczyk, K. Badyda, S. Karellas, E. Kakaras, W. Bujalski, Energy and exergy analysis of adiabatic compressed air energy storage system, Energy 138 (2017) 12-18.

[29] C. Guo, Y. Xu, H. Guo, X. Zhanga, X. Lin, L. Wang, Y. Zhang, H. Chen, Comprehensive exergy analysis of the dynamic process of compressed air energy storage system with low temperature thermal energy storage, Appl. Therm. Eng. 147 (2019) 684-693.

[30] S. Houssainy, M. Janbozorgi, P. Kavehpour, Thermodynamic performance and cost optimization of a novel hybrid thermal-compressed air energy storage system design, J. Energy Storage 18 (2018) 206-217.

[31] Y.M. Kim, Novel Concepts of Compressed Air Energy Storage and Thermo-Electric Energy Storage, $\mathrm{PhD}$ dissertation Ecole polytechnique fédérale de Lausanne, Switzerland, 2012

[32] Y.M. Kim, D.G. Shin, D. Favrat, Operating characteristics of constant-pressure compressed air energy storage (CAES) system combined with pumped hydro storage based on energy and exergy analysis, Energy 36 (10) (2011) 6220-6233.

[33] Y. Mazloum, H. Sayah, M. Nemer, Dynamic modeling and simulation of an isobaric adiabatic compressed air energy storage (IA-CAES) system, J. Energy Storage 11 (2017) 178-190.

[34] A. Arabkoohsar, M. Dremark-Larsen, R. Lorentzen, G.B. Andresen, Subcooled compressed air energy storage system for coproduction of heat, cooling and electricity, Appl. Energy 205 (2017) 602-614.

[35] Z. Han, S. Guo, Investigation of discharge characteristics of a tri-generative system based on advanced adiabatic compressed air energy storage, Energy Convers. Manage. 176 (2018) 110-122.

[36] G. Venkataramani, E. Ramakrishnan, M.R. Sharma, A.H. Bhaskaran, P.K. Dash, V. Ramalingam, J. Wang, Experimental investigation on small capacity compressed air energy storage towards efficient utilization of renewable sources, J. Energy Storage 20 (2018) 364-370.

[37] M. Cheayb, M. Marin Gallego, M. Tazerout, S. Poncet, Modelling and experimental validation of a small- scale trigenerative compressed air energy storage system, Appl. Energy 239 (2019) 1371-1384.

[38] M. Minutillo, A.L. Lavadera, E. Jannelli, Assessment of design and operating parameters for a small compressed air energy storage system integrated with stand-alone renewable power plant, J. Energy Storage 4 (2015) 135-144.

[39] W.M. Kays, A.L. London, Compact Heat Exchangers, third ed., McGraw Hill, USA, 1997.

[40] W. He, J. Wang, Optimal selection of air expansion machine in compressed air energy storage: a review, Renew. Sustain. Energy Rev. 87 (2018) 77-95.

[41] V. Lemort, L. Guillaume, A. Legros, S. Declaye, S. Quoilin, A comparison of piston, screw and scroll expanders for small scale Rankine cycle systems, Proceedings of the 3rd International Conference on Microgeneration and Related Technologies, Napoli (Italy), 2013.

[42] A.P. WeiB, Volumetric expander versus turbine-which is the better choice for small ORC plants, 3rd ASME ORC Conference, Brussels (Belgium), 2015.

[43] P. Vadasz, D. Weiner, The optimal intercooling of compressors by a finite number of intercoolers, J. Energy Res. Technol. 114 (3) (1992) 255-260.

[44] N.M. Jubeh, Y.S.H. Najjar, Green solution for power generation by adoption of adiabatic CAES system, Appl. Therm. Eng. 44 (2012) 85-89.

[45] S.L. Dixon, C.A. Hall, Fluid Mechanics and Thermodynamics of Turbomachinery, seventh ed., Butterworth-Heinemann, UK, 2014.

[46] S.F. Smith, A simple correlation of turbine efficiency, J. R. Aeronaut. Soc. 69 (655) (1965) 467-470.

[47] P.W. Andreas, Z. Gerd, Micro turbine generators for waste heat recovery and compressed air energy storage, 15th conference on Power System Engineering, Thermodynamics \& Fluid Flow-ES-2016, Pilsen, Czech Republic, 2016.

[48] Fundamentals of Heat and Mass Transfer, in: T.L. Bergman, F.P. Incropera (Eds.), Fundamentals of Heat and Mass Transfer, seventh ed., Wiley, Hoboken, 2011.

[49] A. Bejan, G. Tsatsaronis, M.J. Moran, Thermal Design and Optimization, Wiley, New-York, 1996.

[50] SEALL Company, Pneumatic Air Motors, Catalogue PDE2670TCUK, (2014).

[51] H.P. Bloch, A Practical Guide to Compressor Technology, second ed., WileyInterscience, Hoboken, 2006.

[52] C.M. Burt, X. Piao, F. Gaudi, B. Busch, N.F. Taufik, Electric motor efficiency under variable frequencies and loads, J. Irrig. Drain. Eng. 134 (2) (2008) 129-136.

[53] J.J. Proczka, K. Muralidharan, D. Villela, J.H. Simmons, G. Frantziskonis, Guidelines for the pressure and efficient sizing of pressure vessels for compressed air energy storage, Energy Convers. Manage. 65 (2013) 597-605. 